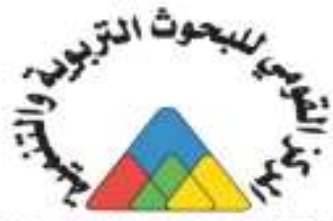

\title{
إسهامات بعض هجالات الاقتصاد الرقمي في رقمنة التعليم الفني هن وجهة نظر الخبراء
}

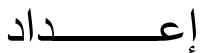 \\ أ.د/ همصمد بميسي ناصف \\ أستاذ علم النفس التربوي \\ رئيس شُبة بحوث التعليم الفني \\ المركز القومي للبحوث التريوية والتنمية \\ E-mail: mohamed.nasef@ hotmail.com
}

$$
\begin{aligned}
& \text { الناش } \\
& \text { المكز التومي للبحوث التربوتتهالثميتبالتاهـة } \\
& \text { جمهورية مصر العربية }
\end{aligned}
$$

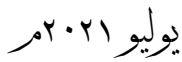


إسهامات بعض بجالات الاقتصاد الرقي في رقمنة التعليم الفني من وجهة تظر الخبراء

\section{إسهاهات بعض هجالات الاقتصاد الرقهمي في رقمنة التعليم الفني هن وجهة نظر الخبراء}

إعداد

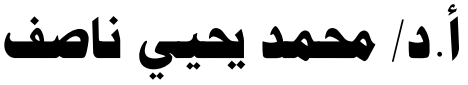

أستاذ علم النفس النزبوي

رئيس شعبة بحوث التعليم الفني

لمركز القومي للبحوث التربوية والتتمية

\section{هستخلص الدراسة:}

هدفت الدراسة تعرف إسهامات بعض الاقتصاد الرقمي في رقمنة التعليم الفني من وجهة

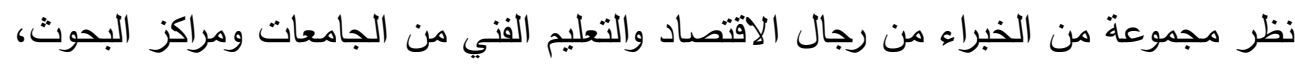

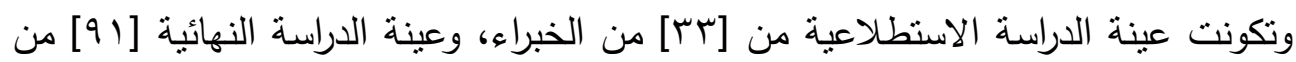

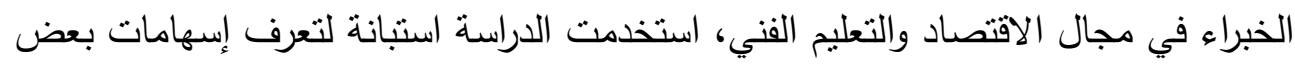
مجالات الاقتصاد الرقمي في رقمنة التعليم الفني، وقد نوصلت نتائج الدراسة إلى قدرة

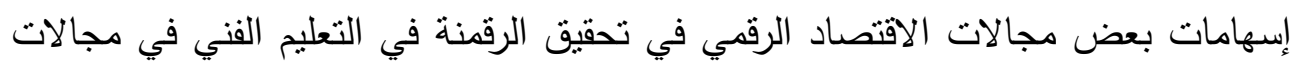

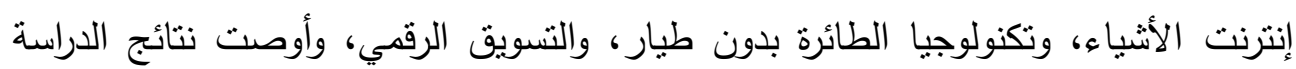

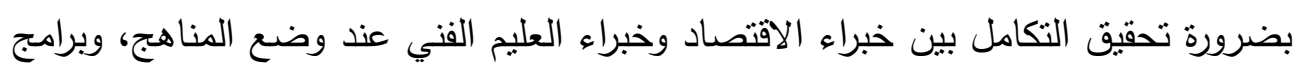
إعداد وتدريب المعلمين بهدف تزويد الطلاب والمعلمين في التعليم الفني بمجالات الاقتصاد

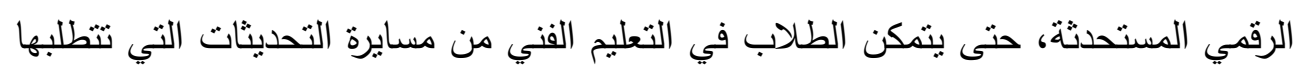

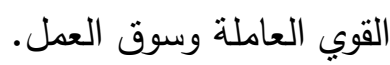

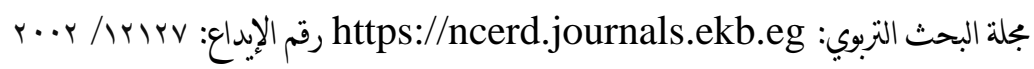

E-ISSN :Y^・0-Y^O\&

ISSN: $\cdot \wedge \Lambda N^{\prime}-17 N V$ 


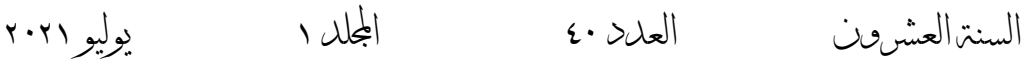 \\ The Contribution of Some Domains of the Digital Economy to the Digitization of Technical Education from the Point of View of Experts
}

Prepared by:

\author{
Prof. Mohammed Yahia Nasef
}

Professor of Educational Psychology

Head of Technical Education Research Division

National Center for Educational Research and Development

\begin{abstract}
:
The study aimed to know the contribution of some digital economy to the digitization of technical education from the point of view of a group of experts from economists and technical education from universities and research centers. The survey sample consisted of [33] experts, and the final study sample of [91] experts in the field of economics and technical education. The study used a questionnaire to know the contribution of some areas of the digital economy to the digitization of technical education. The results of the study found the ability of some areas of the digital economy to achieve digitalization in technical education in the fields of the Internet of things, drone technology, and digital marketing, and the results of the study recommended The necessity of achieving integration between economists and technical education experts when developing curricula, teacher preparation and training programs, with the aim of providing students and teachers in technical education with the new fields of digital economy, so that students in technical education can keep pace with the updates required by the workforce and the labor market.
\end{abstract}

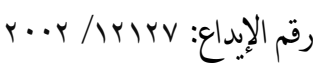

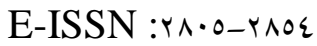

https://ncerd.journals.ekb.eg بحلة البحث التربوي:

ISSN: $\cdot$ ANT-I TAV 
إسهامات بعض بجالات الاقتصاد الرقي في رقمنة التعليم الفني من وجهة تظر الخبراء

\section{إسهاهات بعض هجالات الاقتصاد الرقمي في رقمنة التعليم الفني هن وجهة نظر الخبراء}

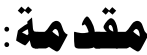

يعتمد الاقتصاد الرقمي على تكنولوجيات أو تقنيات الحوسبة الرقمية، على الرغم من

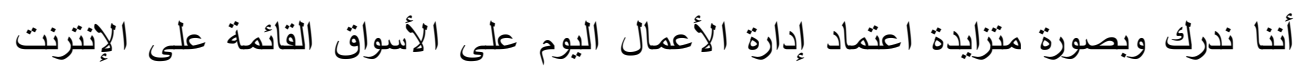

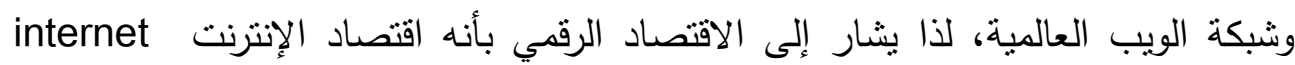

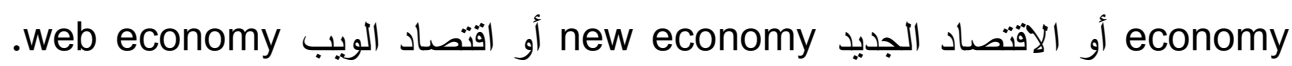
لقد أصبح المجتمع الرقمي digital society، والاقتصاد الرقمي digital economy حقيقة

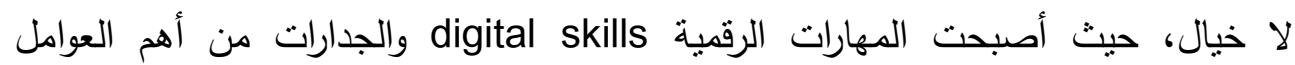
المسهمة في تحقيق النمو المهني والثخصي للطلاب، حيث شهدت السنوات الأخيرة من هذا

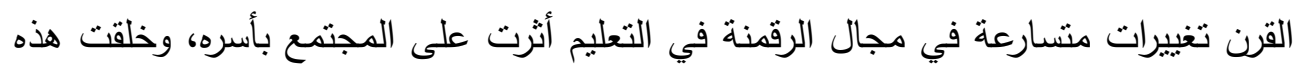

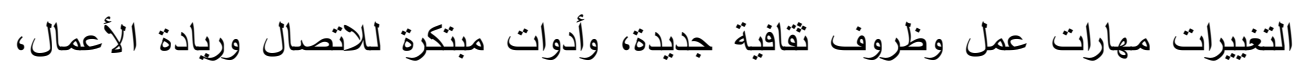

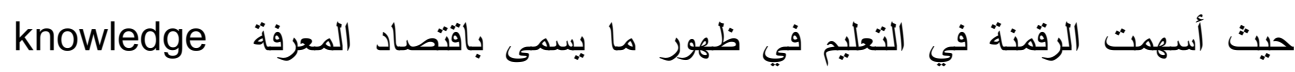
economy وأصبحت المعرفة من أهم الموارد الاقتصادية الإستراتيجية، كما أسهوت الرقمنة في تسهيل الريل

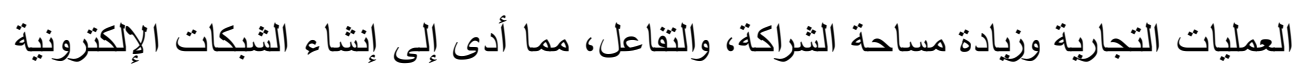

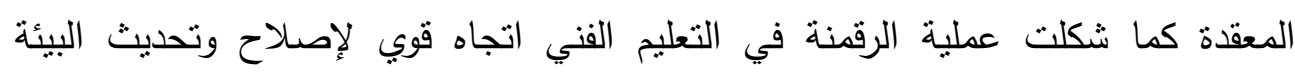
التعليمية في الدارس لتواكب التوجهات العالمية، حيث تتطلب عملية الرقمنة تحويل

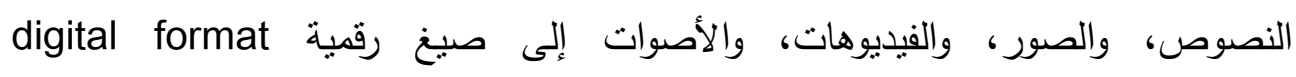
.(Bejinaru, 2017)

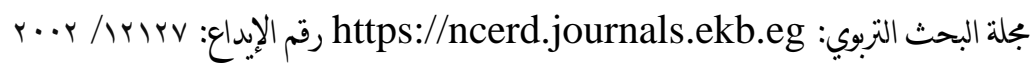

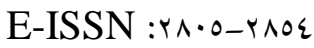

ISSN: $\cdot \wedge \Lambda \mu-I T \Lambda V$ 
وتعمل الضروريات الاقتصادية والاجتماعية إلى جانب الابتكار والتجديد التكنولوجي على تطور ونمو الاقتصاد الرقمي، إلى جانب حدوث مستويات مرتفعة من النمو وبخاصة النها في البلدان النامية، وأن الاقتصاد الرقمي يقوم على إدخال التطبيقات التكنولوجية الأوسع في لئي

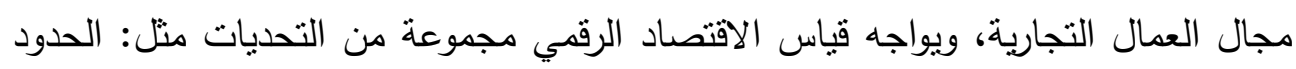

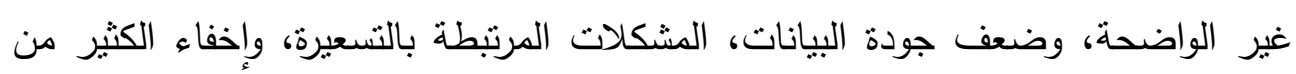
الأنشطة الرقمية (Bukht \& Heeks, 2017,20). لقد مرت البشرية بأربعة أنواع من الثورات الصناعية تمخض عن الثورة الصناعية

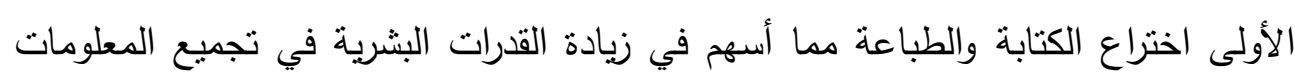
accumulating information أسهم في تعرف البشرية على التلغرافات أو البرقيات telegraph، والهاتف telephone، وني والراديو radio، وهذا قد أسهم بصورة فعالة في إحداث تواصل في المعلومات information communication المعالجة الدقيقة microprocessor technology، مما أسهر في التوصل إلى صناعة الكمبيوترات الثخصية، وهذه الثورة قد أسهمت بصورة مباشرة في إنتاج production،

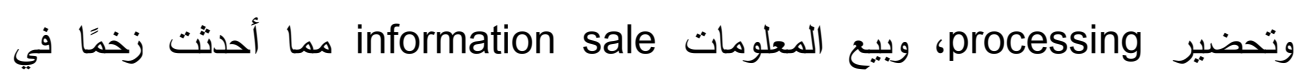
الحضارة الإنسانية، فقد أسهمت هذه الثورة في الانتقال إلى مجتمع المعرفة وظهور أثكال

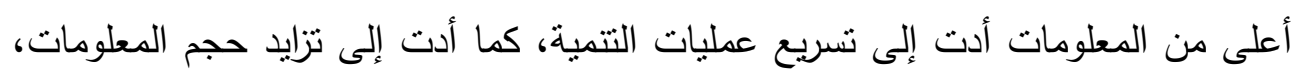
حيث أسهم استخدام الرموز الرقمية digital codes نسهيل تخزين المعلومات والتعامل معها ونقلها. كما أسهوت تقنيات المعلومات الرقمية في تحليل وإنتاج وتبادل المعلومات وزيادة فعالية استخدامها في تتمية المجتمع، وتمخض عن الثورة الصناعية الرابعة ظهور إنترنت

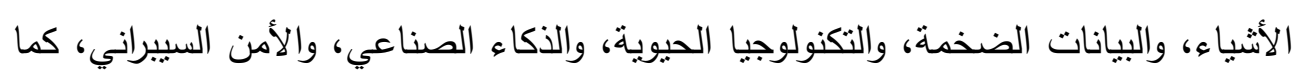

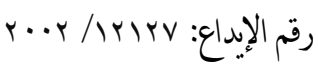

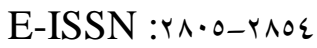

https://ncerd.journals.ekb.eg بملة البحث التربوي:

ISSN: $\cdot \wedge \Lambda \mu-17 \Lambda V$ 
إسهامات بعض بجالات الاقتصاد الرقمي في رقمنة التعليم الفني من وجهة تظر الخبراء

قامت العلاقات الاقتصادية والاجتماعية الثقافية في المجتمع على استخدام تقنيات الاتصالات الرقمية، وهي شكل اقتصادي جديد سُمي باسم الاقتصاد الرقمي والذي يعتمد

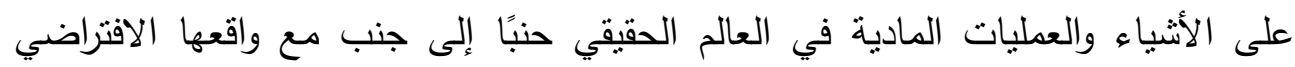
.(Bakeeva, Pastukhova \& Romanova,2019) virtual reality وإذا كان التعليم هو الأساس الذي يُسهم في تطوير المعلومات فإن الفضاء التعليمي ينمو ويتطور بسرعة بسبب تطور البيئة الرقمية، حيث أسهم ذلك في إنشاء الكتب المدرسية

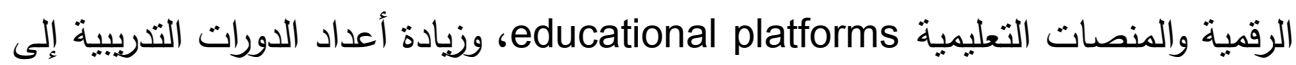
الملابين، كما أسهر مجتمع المعرفة والمعلومات المتزايدة في نمو وتطوير القطاعات الاجتماعية والاقتصادية في المجتمع مما ساعد في ظهور ما يسمى عصر الاقتصاد الرقمي ولمعي .(digital economy age)

لقد أصبح إضفاء الطابع المعلوماتي على الحياة informatization of life، هو من أهم الاتجاهات العالمية، التي تحرص على أن يكون التعليم بمثابة الوثيقة المفتاحية

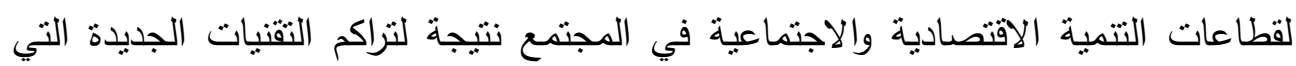

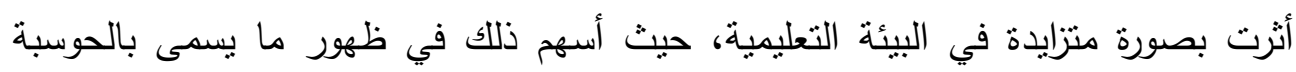

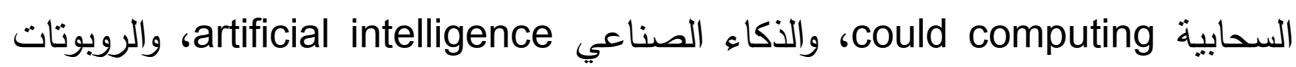
robotics وهندسة النانو Nano-engineering، وإنترنت الأشياء، وأحدثت هذه التقنيات تغييرات سريعة وجذرية في بنية التعليم، إلى جانب منطلبات البيئة الرقمية التي أسهمت في وهني

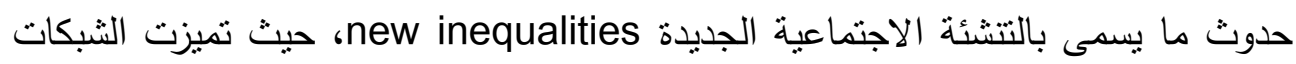

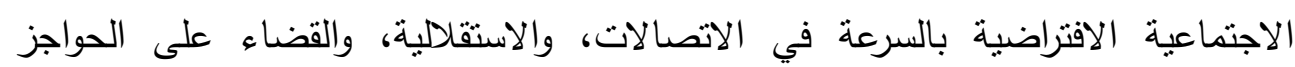
الجغرافية، واللغوية، والثقافية.

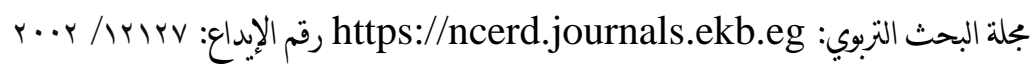

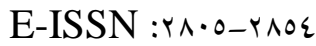

ISSN: $\cdot \Delta \Lambda \mu-I T \Lambda V$ 
كما أسهمت الرقمنة في التعليم الفني في تدعيم المهارات الرقمية لدى الطلاب والتي

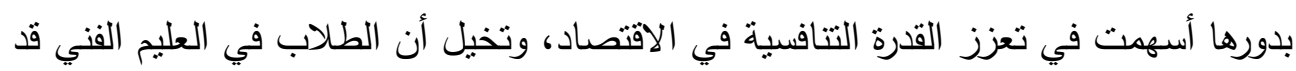
تم تدريبهم على القطع والخراطة باستخدام أفضل المعدات، ولكن عمليات التوظيف الآن

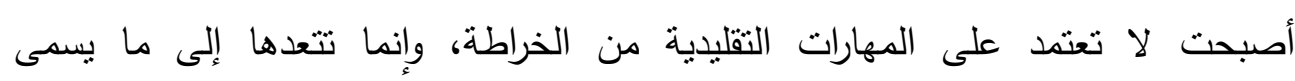
internet of مثل: من إنترنت الأثياء things، والطابعات ثلاثية الأبعاد، فالرقمنة شُشهم في تعزيز المهارات والكفاءات الفردية، وجعل عملية التعلم أكثر مرونة، وأكثر جاذبية كما أسهمت الرقمنة في تعزيز جودة التعليم الفني. إن التحول نحو الرقمنة في التعليم الفني يجعل عمليات التعليم ميسورة وأقل تكلفة وأكثر إثارة وأكثر قدرة على الاستجابة لاحتباجات الطلاب، وأنماط تعلمهم حيث تتم عمليات التعلم وفقًا لاحتياجات الطالب، حيث يُسهم في تزويد الطلاب بالمهارات التي تتطلبها الصناعة

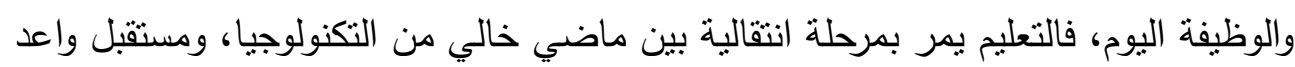

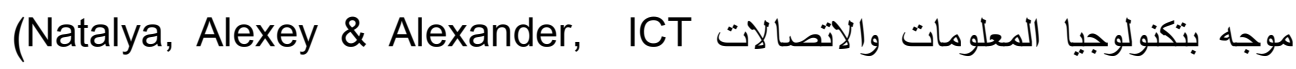

\section{هشكلة الدراسة:}

تنبلور مشكلة الدراسة في النقاط التالية:

(Atzori et al., 2010; Mattern \& : ما أشارت إلبه نتائج دراسات مثله: Floerkemeier, 2010; ITU, 2012; Porter \& Heppelmenn, 2014; Fleisch et al., 2014; Vermesan et al.,2014; مجالات الإنترنت الرقمية مثل: إنترنت الأثياء في رقمنة التعليم الفني، حيث توصلت

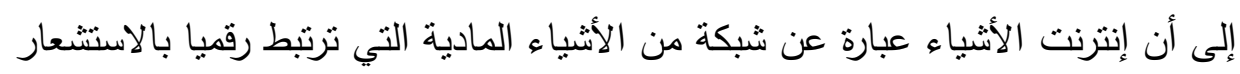

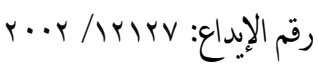

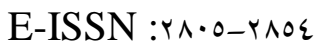

https://ncerd.journals.ekb.eg بجة البحث التربوي:

ISSN: • ANץ-I TAV 
إسهامات بعض بجالات الاقتصاد الرقمي في رقمنة التعليم الفني من وجهة تظر الخبراء

sense، والمراقبة monitor لتحقيق التفاعل داخل وخارج الثركات وسلسلة التوريد الخاصة مما يوفر المرونة والرؤية ومشاركة المعلومات وتيسير التخطيط، والتحكم، والتتسيق بين عمليات التوريد، ويتم تجهيز الآلات والأجهزة الخاصة بالاستشعار والاتصال بالإنترنت التي تيسر عملية جمع البيانات وتخزين هذه البيانات في الخدمات

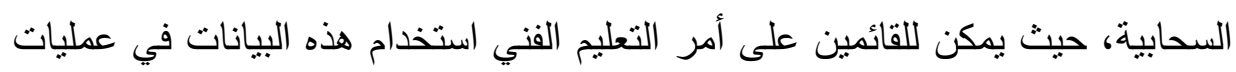

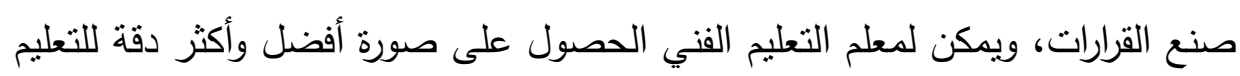

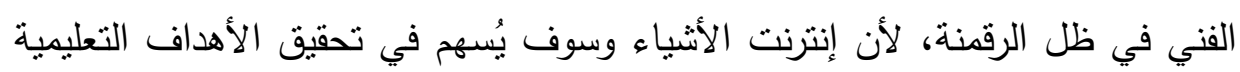

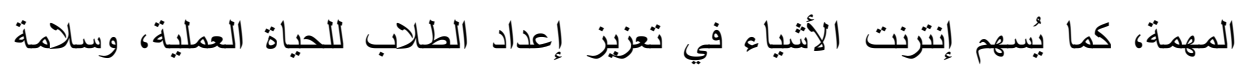

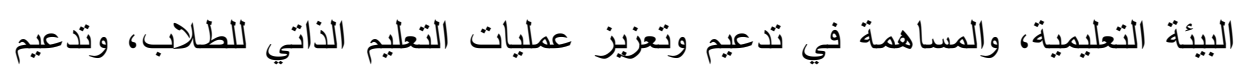

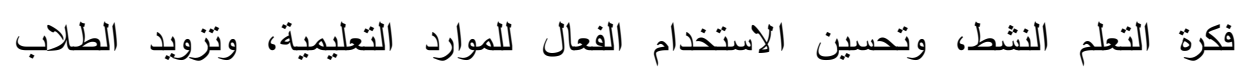

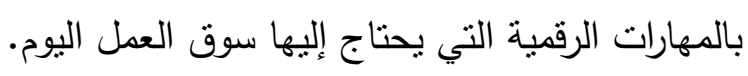

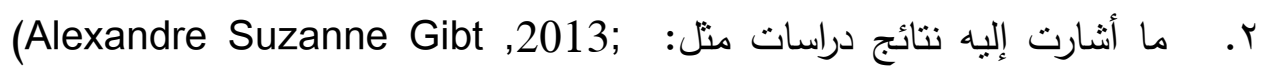
Preble ,2015; Birtchnell \& Gibson ,2015; Jordan ,2015; Stijn Poslema ,2015; Cruz Silva, 2016; Petrinjak, 2016; Mishra \& Koehler ,2016; Carnahan, 2016; Strimel, Barlholomew \& Kim, (2019) 2017; Ng,\& Cheng من قدرة إسهامات بعض مجالات الإنترنت الرقمية

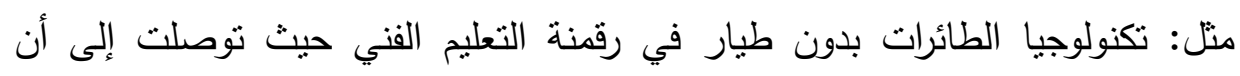

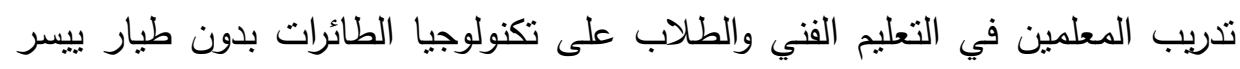

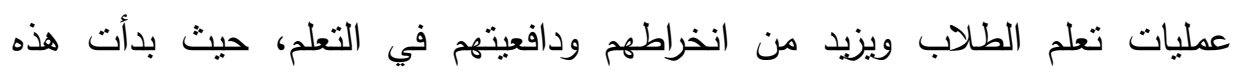

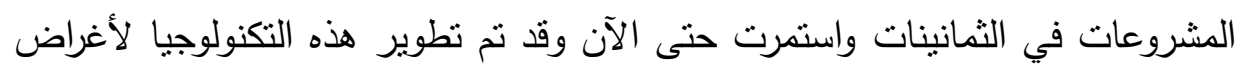

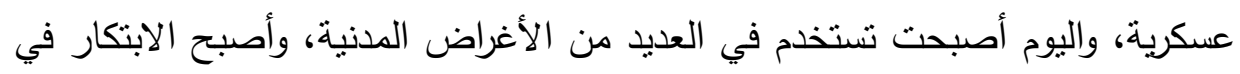

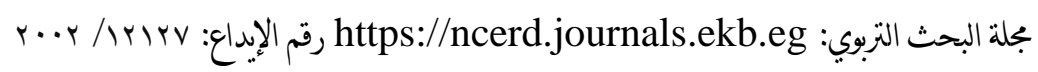

E-ISSN :Y^・0-Y^O\&

ISSN: $\cdot \wedge \Lambda \uparrow-17 \Lambda V$ 
تكنولوجيا الطائرات بدون طيار يسير بوتيرة منسارعة، والطائرة بدون طيار هي عبارة

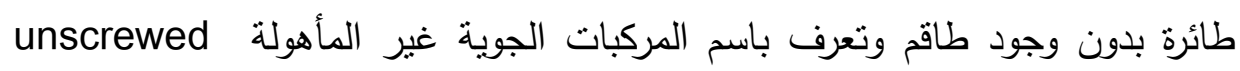
unmanned aircraft aerial vehicles systems، هي بمثابة روبوت طائر يمكن التحكم فيه عن بعد أو الطيران بضرورة

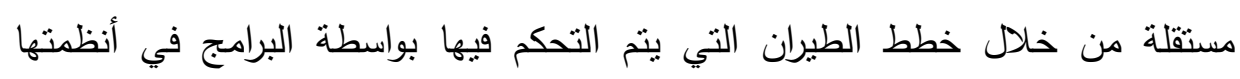
المدمجة، والتي تعمل جنبًا إلى جنب مع أجهزة الاستشعار الموجودة على منن الطائرة

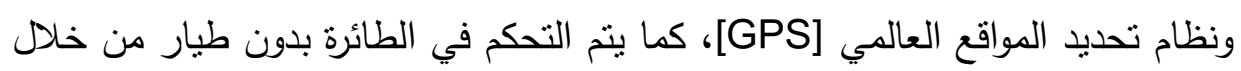

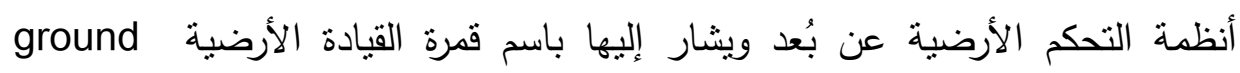
cockpit

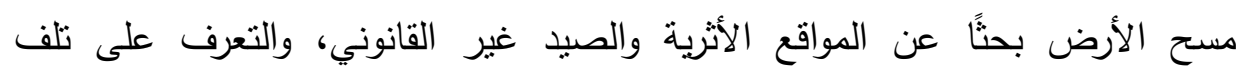
المحاصيل، ودراسة العواصف البرية، كما يمكن استئجار الطائرة بدون طبار في التحليق التئ ونئ

$$
\text { فوق الأفق، والتقاط صور أو مقاطع فيديو للطبيعة. }
$$

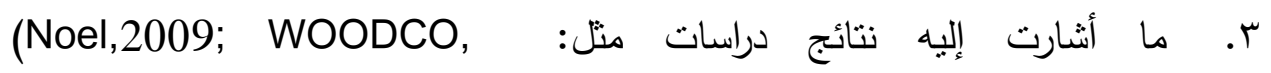
2013; Stoke, 2013; Dhote, Jog, Gavade\& Shrivastava ,2015; Pride\& Ferrel, 2016; Pineiro-Otero \& Martinez-Rolan, 2016; (Khausik ,2017; Get craft, 2017; Kusumawati, 2019) قدرة إسهامات بعض مجالات الاقتصاد الرقمي مثل: التسويق الرقمي في رقمنة التعليم الفني، حيث أوضحت نتائجها أن التسويق الرقمي يُعد من الأمور بالغة الأهمية اليوم

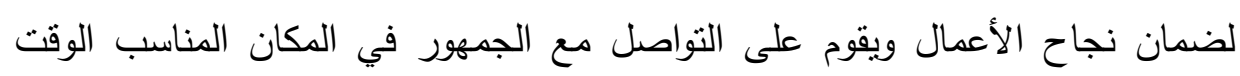

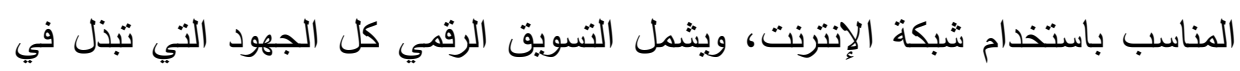

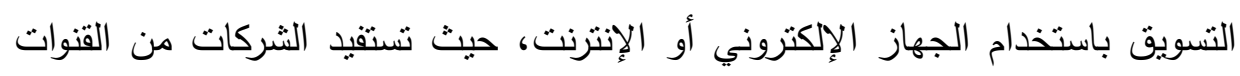

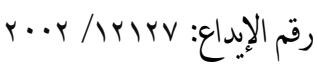

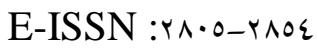

https://ncerd.journals.ekb.eg بكلة البحث التربوي:

ISSN: $\cdot \wedge \wedge \mu-I T \wedge V$ 
إسهامات بعض بجالات الاقتصاد الرقي في رقمنة التعلم الفني من وجهة ظظر الخبراء

الرقمية منل: محركات البحث search engines، والوسائط الاجتماعية Social media

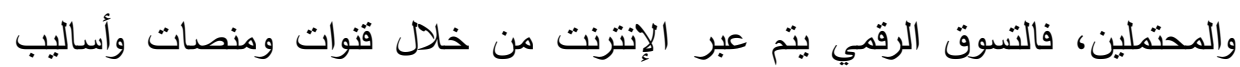
مختلفة سواء عبر موقع الويب الخاصة بالشركة أو عبر البريد الإكتروني أو عبر الإنرئ

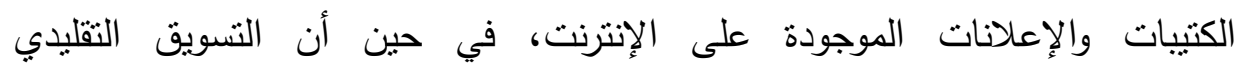
traditional marketing أو التسويق المادي، ومن ثم فإن تدريب المعلمين والطلاب على بعض مجالات

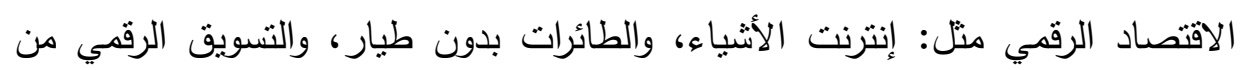

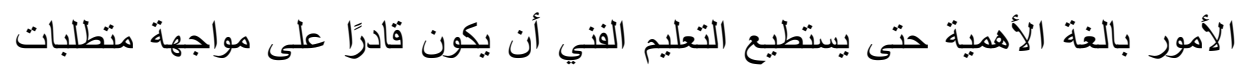
العصر الحديث، وتلبية احتباجات سوق العمل، وفي ضوء ما سبق نتبه لتبلور مشكلة الدراسة في الأسئلة التالية:

أسئلة الدراسة:

ـ ما مجالات إسهامات الاقتصاد الرقمي في رقمنة التعليم الفني؟ ويتفرع هذا السؤال إلى

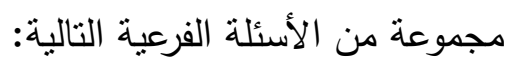
ا. ما مجال إسهامات إنترنت الأثياء في رقمنة التعليم الفني؟ الاسئه

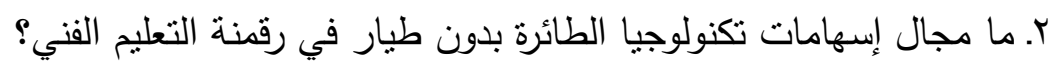

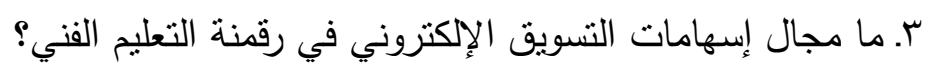
أهداف الدراسة: مال:

$$
\text { هدفت الدراسة تعرف مجالات إسهامات: }
$$

r. تكنولوجيا الطائرة بدون طيار في رقمنة التعليم الفني؟ التئ

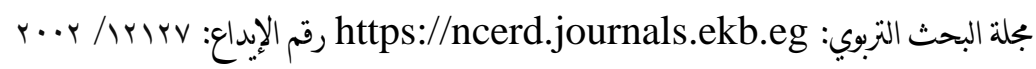

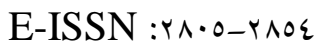

ISSN: $\cdot \Delta \Lambda \mu-I 7 \Lambda V$ 
r. التسويق الإلكتروني في رقمنة التعليم الفني؟

\section{أهمية الدراسة:}

• تتمنل الأهمية النظرية في الاطلاع على الأدبيات العربية والأجنبية التي تتاولت تعرف

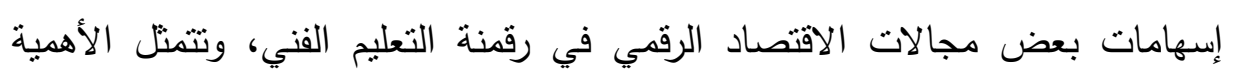
التطبيقية في وضع أداة تستخدم في تعرف إسهامات بعض مجالات الاقتصاد الرقمي في رقمنة التعليم الفني. • يعد الاقتصاد الرقمي بمثابة رأس المال البشري القابل للتسويق، وهو يشكل المدخل الرئيسي في مساعدة الدول على تحقيق الدخل المرتفع لمواطنيها، فالعمال المهرة هم المفتاح لنمو أي دولة اقتصاديًا، وتتمية رأس المال البشري فيها، فالبلاد التي تمنلكي

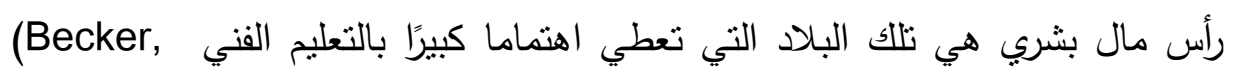
.Murphy \& Tamura,1994) • مساعدة المسؤولين في وزارة التربية والتعليم لتسليط الضوء على إسهامات بعض ف التص مجالات الاقتصاد الرقمي في رقمنة التعليم الفني بعد مناداة خبراء التعليم في العالم، لماءه ومنها بريطانيا بضرورة الاهتمام بالتأثيرات التي يحدثها الاقتصاد الرقمي في رقمنة

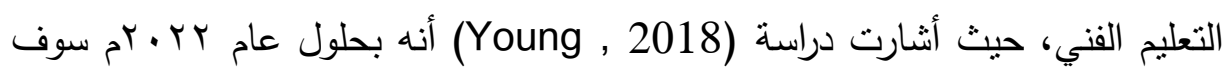
يكون هناك أكثر من ب,r مليون وظيفة شاغرة في التعليم الفني منل: الوظائف المرتبطة بالتصنيع المتقدم هن هنرن سعى وزارة التربية والتعليم من خلال الخطة الإستراتيجية للتعليم قبل الجامعي

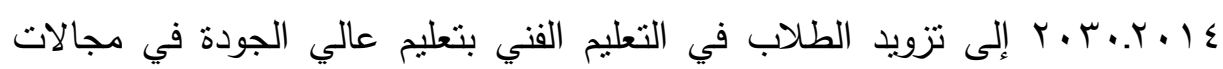
المعرفة والمهارات المتقدمة بما يتتاسب مع قدراتهم الفردية بجميع مراحل التعليم قبل الجامعي، من خلال الأهداف الإستراتيجية المتمتلة في دعم ورعاية الطلاب في مدارس بله 
إسهامات بعض بجالات الاقتصاد الرقمي في رقمنة التعليم الفني من وجهة تظر الخبراء

التعليم قبل الجامعي، وتطوير جودة التعليم بمدارس التعليم الفني وتطوير مراكز

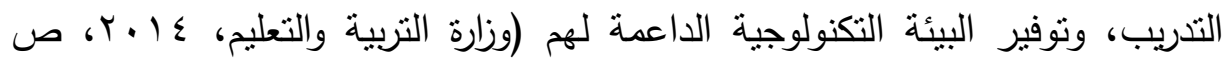
$\cdot(1 \cdot \varepsilon$

يقتصر البحث الحالي على مجموعة من الخبراء في مجال الاقتصاد والتعليم الفني. هصطات الدراسة:

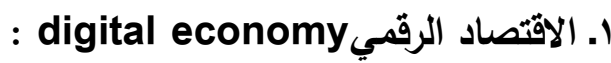

يعرف الاقتصاد الرقمي بأنه اقتصاد يعمل بصورة أساسية من خلال استخدام الوسائل الرقمية التكنولوجية، وخاصة المعاملات الإلكترونية التي تتم من خلال استخدام الإنترنت (Bukht \& Heeks, 2017, 9) (أو هو عبارة عن اندماج لمجموعة من التقنيات للقيام

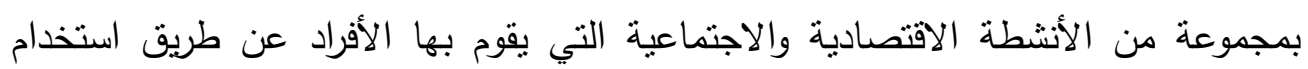

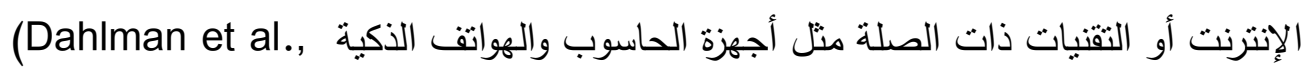
(2016. كما يُعرف الاقتصاد الرقمي بالقدرة على الوصول الرقمي للبضائع والخدمات

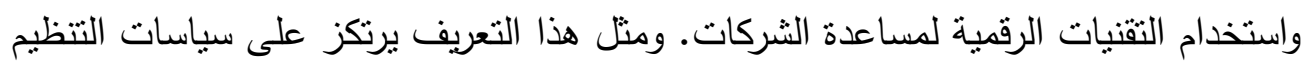
وآليات دعم الاقتصاد الرقمي (House of Commons, 2016).

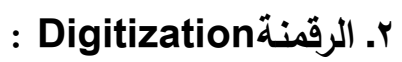

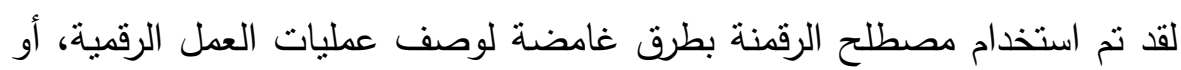

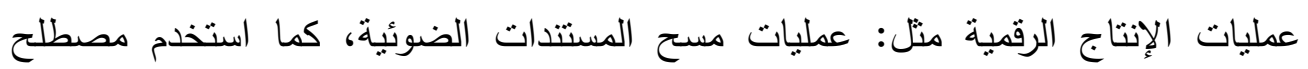
الرقمنة ليشير إلى العواقب الناجمة عن دمج أو إدخال التقنيات الجديدة أو الحديثة في عمليات العمل الحالية (Wolf \& Strhschen, 2018; Mertens \& Wiener, 2018). r. التعليم الفني Technical education:

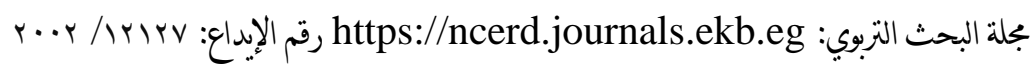

E-ISSN :YN・O-YNO\&

ISSN: $\cdot \wedge \Lambda ץ-17 N V$ 
يرى Wapmuk (2011) أن التعليم الفني في كل دول العالم يقصد به التعليم الذي يعمل على تزويد المنتسبين إليه بالأداء الماهر Skillful performance، والمهام العلمية practical tasks بهدف تمكينهم empowerment وتزويدهم بالمهارات العملية، والكفاءات competencies التي تساعدهم في أن يكون لهم دور إنتاجي productively بهنة بهات في المهن الصناعية industrial، أو التجارية commercial، وهو التعليم الوظيفي

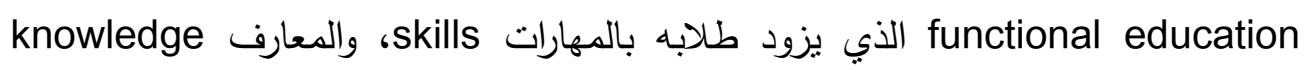
والاتجاهات attitudes بهدف تحقيق التوظيف الفعال effective employment لهم في بردي جميع المهن، ويري (Dougherty, 2016) أن النعليم الفني هو التعليم الذي يسمح للطلاب

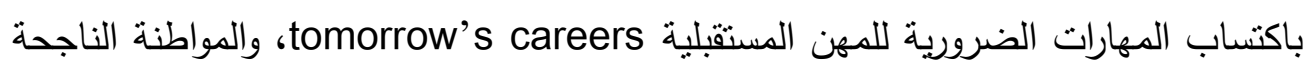

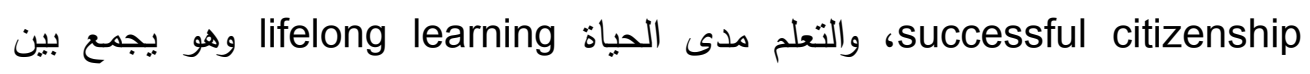
المعرفة الأكاديمية والمهارات العملية التطبيقية لإعداد الطلاب للقوي العاملة workforce

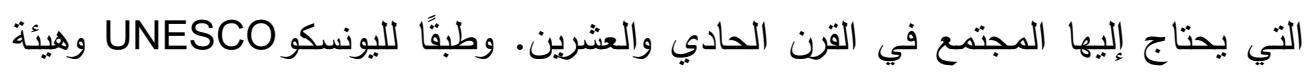

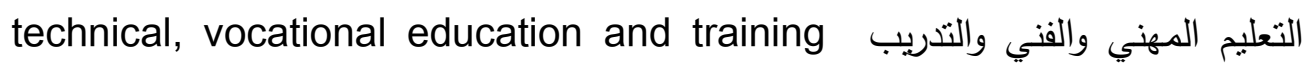
فإن التعليم الفني ينظر إليه على أنه مصطلح شامل يشير إلى الجوانب في العملية

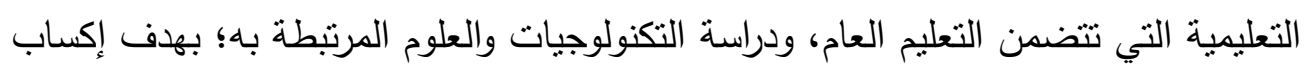
الطلاب المعرفة والمهارات العلمية والاتجاهات المرتبطة بجميع المهن في مختلف قطاعات ودريه الحياة الاقتصادية والاجتماعية، بالإضافة إلى ذلك فإن التعليم الفني ينظر إليه على أنه جزء

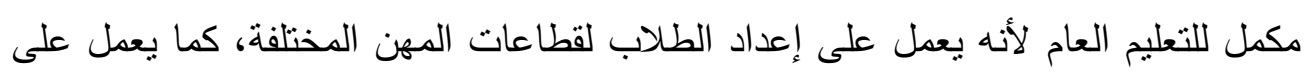

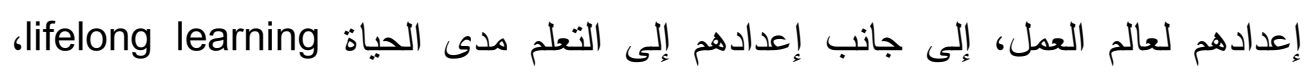
وإعدادهم للمواطنة المسؤولة responsible citizenship، لتحقيق وتعزيز التتمية المناسبة إعلى وتخفيف حدة الفقر alleviating poverty. إن التعليم الفني هو نوع من التعليم يُصمم

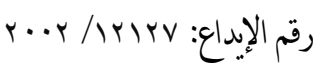

E-ISSN : $\curlyvee \wedge \cdot 0-\curlyvee \wedge \circ \varepsilon$ https://ncerd.journals.ekb.eg بلة البحث التربوي:

ISSN: $\cdot \wedge \Lambda \mu-17 \Lambda V$ 
إسهامات بعض بجالات الاقتصاد الرقمي في رقمنة التعليم الفني من وجهة تظر الخبراء

بطريقة تقنية منظمة لتمكين المعلم والمتعلم، والمدرب والمتدرب من اكتساب المعارف الأساسية، والمهارات، والقدرات، وتحقيق الفهم، وتعديل الاتجاهات، بهدف مساعدة الطلاب الفيل

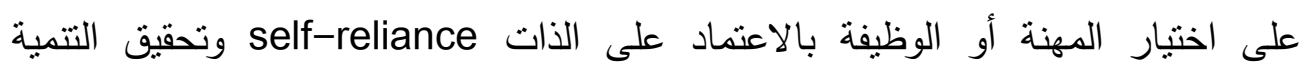
للمجتمع الذي بعيش فيه، حيث أثنارت دراسة (2015) Adelakun, Oviawe \& Barfa إلى أن التعليم الفني هو التعليم الذي يُمكن المنتسبين إليه بأن يصبحوا أفراد نشيطين في

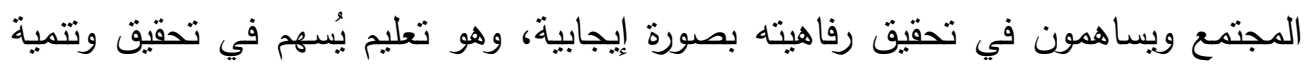

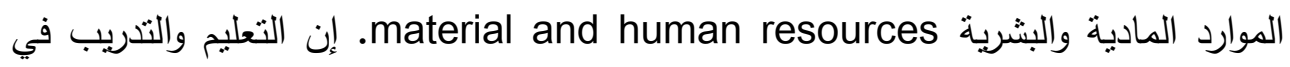
المجال النقني والمهني كما نوضحه هيئة [TVET يساهمان في تعزيز فهم حقوق الإنسان واحترامها؛ والنهج الاندماجي والإنصاف والمساواة بين الجنسين والتتوع النقافي وفي تعزيز الرغبة في التعلم مدى الحياة وتعلم العيش معًا والقدرة على ذللك، وكلها أمور أساسية الأنية

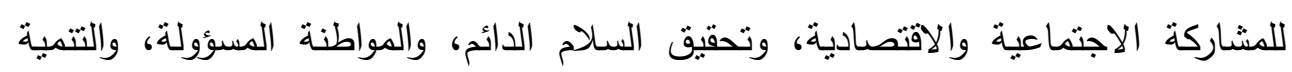

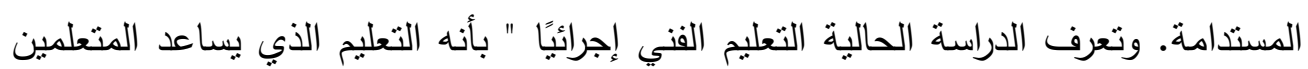

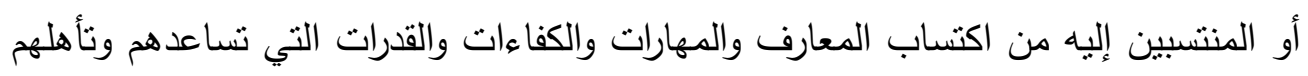
للالنحاق بسوق العمل، وتدفعهم للتعلم مدى الحياة".

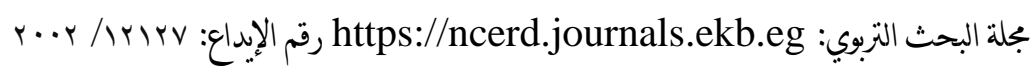

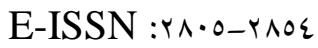

ISSN: $\cdot \wedge \wedge \mu-17 \wedge \vee$ 


\section{الإطار النظري للدراسة والدراسات السابقة:

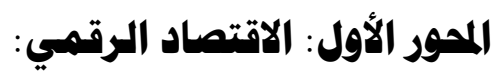 ا ـ مفهوم الاقتصاد الرقمي في التعليم الفني:}

يُسهر الاقتصاد الرقمي في التعليم الفني في تزويد الطلاب بالمهارات الرقمية المستقبلية، والتي تُعد من العوامل الأساسية المسهمة في توفير الفرص والوظائف الجديدة للطلاب، كما يُسهم الاقتصاد الرقمي في التعليم الفني في تحقيق التكامل بين التخصصات المختلفة وتعزيز الأسواق الرقمية، والاستثمار ، وتحسين بيئة الأعمال وتحسين مناخ الاستثمار فئين وتطوير المهارات الرقمية. وينمو الاقتصاد الرقمي بسرعة كبيرة لا سيما في البلدان النامية

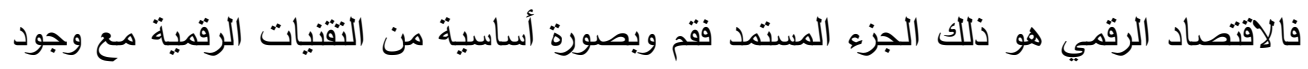
نموذج أعمال يقوم على السلع أو الخدمات الجديدة، ويشكل الاقتصاد الرقمي ما نسبته [0\% من الناتج الحلي الإجمالي، [ب\%] من العمالة العالمية وكان لسكان شمال العالم نصيب الأسد من الاقتصاد الرقمي حتى الآن، حيث ينمو الاقتصاد الرقمي في الثمال بسرعة أكبر

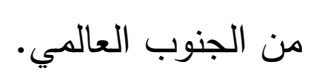

ويقوم الاقتصاد الرقمي على التقنيات الرقمية الحديثة في إجراء الأعمال من خلال

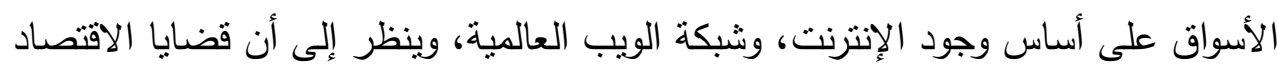

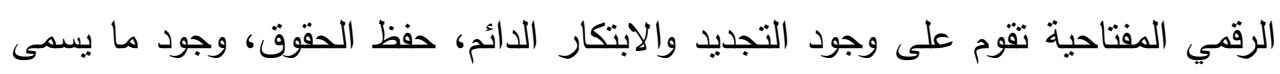

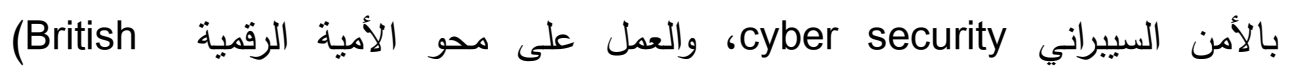
.Computer Society, 2014) r. أهم المؤشرات الدالة على تطور الاقتصاد الرقمي في التعليم الفني: وضع الاتحاد الأوروبي [0] مؤشرات للحكم على نمو وتطور الاقتصاد الرقمي تمثلت 
إسهامات بعض بجالات الاقتصاد الرقمي في رقمنة التعليم الفني من وجهة تظر الخبراء

$$
\text { الاتصال connectively: وتتمنل في جودة نطاق عريض ومتتقل بسرعة. }
$$

المهارات الأساسية لرأس المال البشري: human capital basic skills واستخدام

$$
\text { الإنترنت والمهارات المتقدمة والمتطورة. }
$$

استخدام الإنترنت، واستخدام المحتوى والتواصل والتفاعل عبر الإنترنت بين المواطنين. • تكامل بالتكنولوجيا الرقمية ورقمنة الأعمال التجارية الالكترونية E-commerce. • توافر الخدمات العامة الحكومية الإكترونية الرقمية (Bukht, \& Heeks,2017). ـ مجالات الاقتصاد الرقمي المسهمة في رقمنة التعليم الفني: تُسهم مجالات الاقتصاد الرقمي في رقمنة التعليم الفني من خلال: ا. إنترنت الأثياء Internet of things [IOT]

$$
\text { مفهوم إنترنت الأشياء: }
$$

تعود أصول المصطلح إلى أكثر من [10] عامًا وبالتحديد في عهد ماساشوست

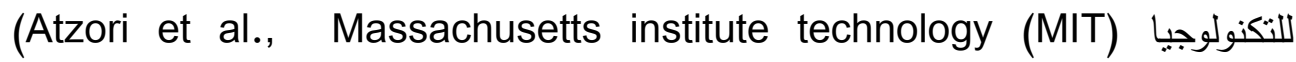
2010; Mattern \& Floerkemeier, 2010) إنترنت الأشياء على أنه عبارة عن النية التحتية العالمية لمجتمع المعلومات القادرة على هلى تقديم الخدمات المتقدمة عن طريق الربط بين الجوانب المادية والجوانب الافتراضية للأثياء (ITU, لى أساس المعلومات القائمة والمتطورة، والقابلة لتشغيل تكنولوجيات التواصل .2012) وهناك تعريفات أخرى تتظر على إنترنت الأشياء على أنه بمثابة بروتوكولات الإنترنت internet protocols على التحديات التي تواجه إنترنت الأشياء مثل التحديات المرتبطة بعمليات التخزين، والبحث، وتتظيم الكميات الكبيرة من المعلومات (Atzori et al., 2010).

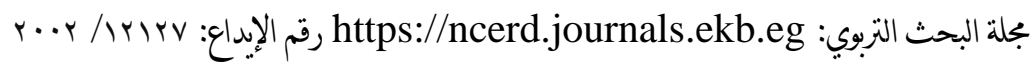

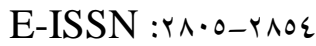

ISSN: $\cdot \Delta \Lambda \mu-I T \Lambda V$ 


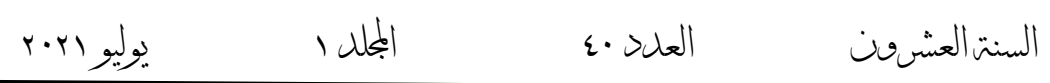

. مجالات تطبيق تقتيات إنترنت الأثشياء في التعليم الفني:

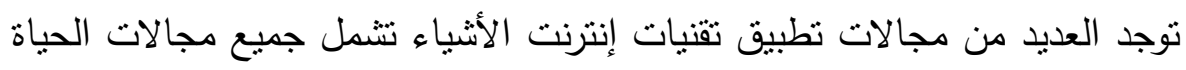

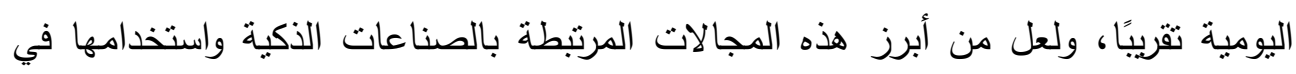

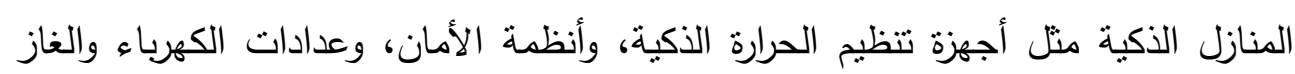

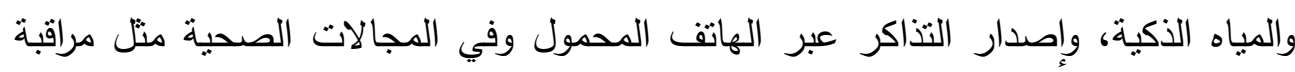

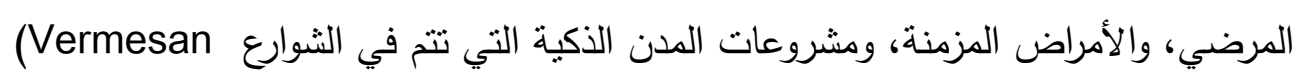
.et al.,2014) كما أسهم إنترنت الأشياء في رقمنة الوظائف والقدرات الرئيسة المرتبطة بالصناعات

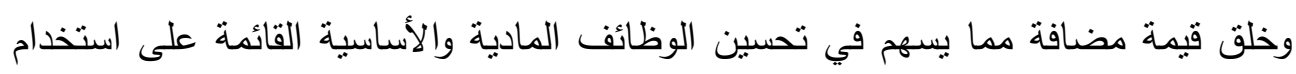

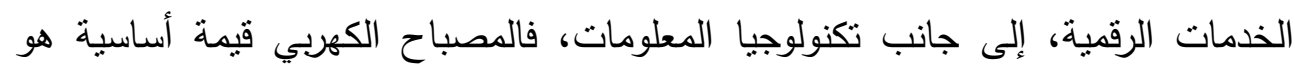

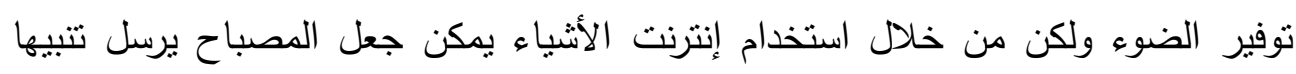

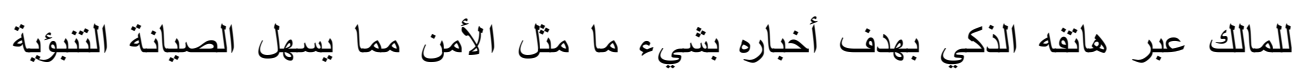

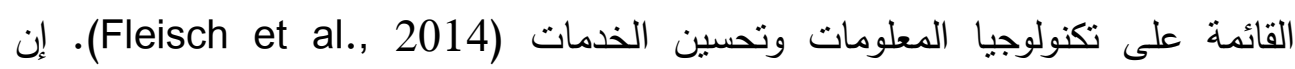

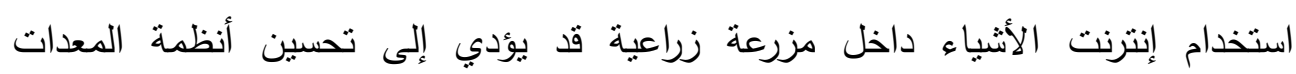

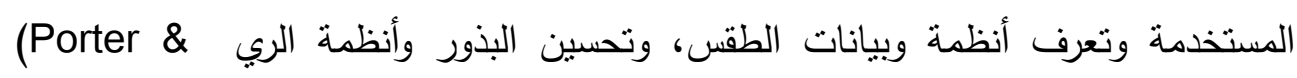

.Heppelmenn, 2014) r. ت كنولوجيا الطائرات بدون طيار:

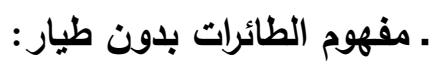

هي عبارة مركبة جوية aerial vehicle بدون طيار تكون موجهة عن بعد، كما

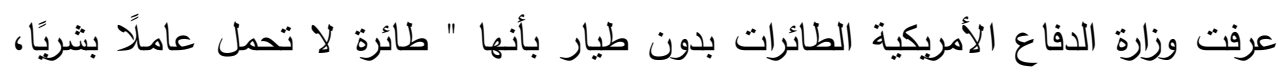

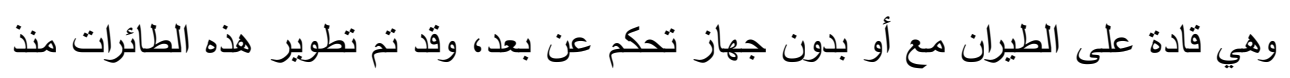

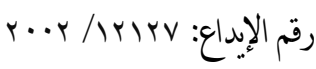

https://ncerd.journals.ekb.eg بجلة البحث التربوي:

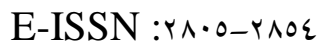

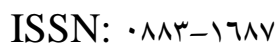


إسهامات بضض بجالات الاقتصاد الرقمي في رقمنة التعليم الفني من وجهة نظر الخبراء

الحرب العالمية الأولى لدعم القوة العسكرية لأغراض الاستطلاع والضربات الصاروخية، ويتزايد استخدام هذه الطائرات الآن في الولايات المتحدة الأمريكية لأنها نسهم في تقليل الخسائر في الحروب (Pearcy, 2015). وفي الحروب التي خاضتها أمريكا في أفغانستان والعراق انتشرت الطائرات بدون طبار على نطاق واسع، حيث استخدمت كأجهزة متفجرة لنن الهجوم (Preble, 2015). ومع التطور التكنولوجي تزايد استخدام هذه الطائرات في الأغراض المدنية، وهي تأخذ

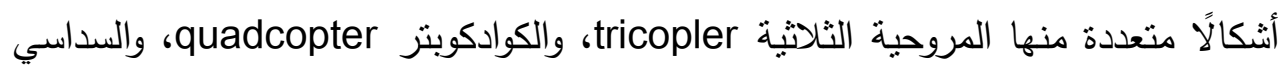
hexacopter حجمها أو حسب مدى طيرانها أو حسب المعدات المتصلة بها، أو حسب قدرتها على (Dronepedia, الطيران عاليًا أو حسب إمكاناتها في الذهاب إلى المناطق الخطرة .2017)

لقد تم استخدام هذه الطائرات في أغراض مدنية منّ: تحديد مكان الأشخاص المفقودين في مهمات البحث والإنقاذ، وأيضًا تم استخدامها في مكافحة الحرائق، حيث يمكنها اختراق الدخان، وفي القبض على المجرمين في المناطق الثاسعة عند تزويدها ببعض الكاميرات لمساعدة رجال الثرطة، أو في إعداد التقارير الإخبارية أو في تصوير

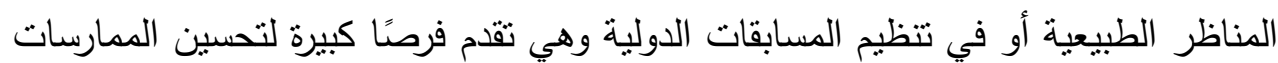
في حياتتا اليومية (Lee, 2018).

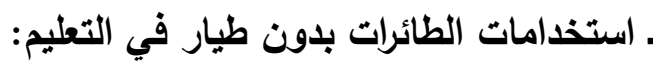

حاول مجموعة من العلماء أمثال: بن تومي سليمة \& حياهم سعاد، بونار صفية

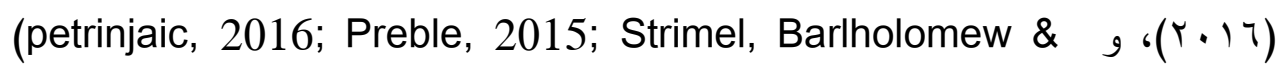
(دim, 2017)

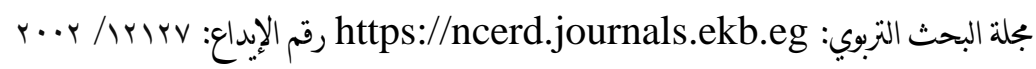

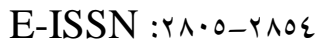

ISSN: $\cdot \Delta \Lambda \mu-I T \Lambda V$ 
والرياضيات، حيث حاول المعلمين تعليم الطلاب في هذه المدارس الفنية تعليم الطلاب كيفية استكثاف التكنولوجيا المضمنة في الطائرات بدون طيار • حيث تم التدريس للطلاب في فصول الهندسة أو الفيزياء، حيث بدأ المعلم مشروعًا يطلب فيه من الطلاب بناء طائرة بدون طبار، حيث كان للطلاب القدرة على تطوير فههم لمواد البناء، وأجهزة الاستشعار ونظام التحكم، حيث تعلم الطلاب بعض المفاهيم الفيزيائية المهمة في هذا الثأن مثل:

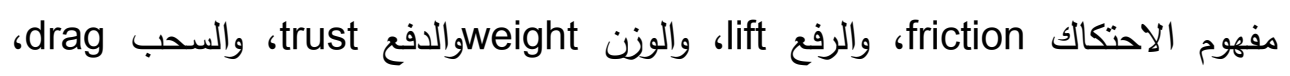
والدوامة vortex، والمماطلة Stall، حيث طلب الطلاب من المعلم في الدراسة التي قام بها

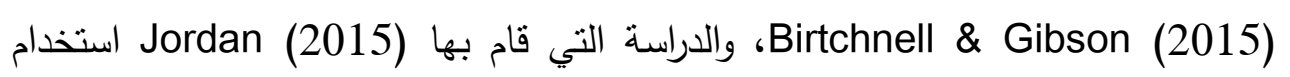
الطائرة بدون طيار في التقاط صور جوية للمناظر الطبيعية في العمل الميداني الجيولوجي

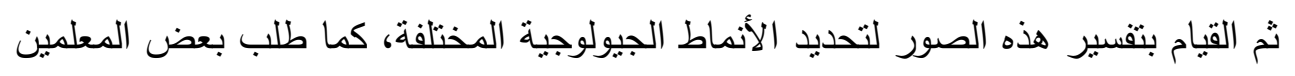

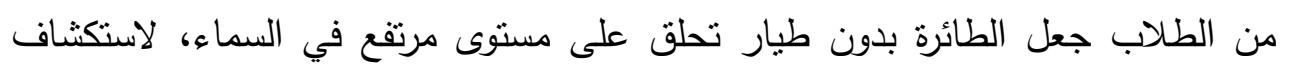

ملامح الأرصاد الجوية meteorological features (Petrinjak,2016). كما طلب معلم آخر من الطلاب جعل الطائرة بدون طيار تسير في مسارات محددة باستخدام برنامج حاسوب، من أجل تعزيز مهاراتهم في مجال البرمجة، حيث استطلاع

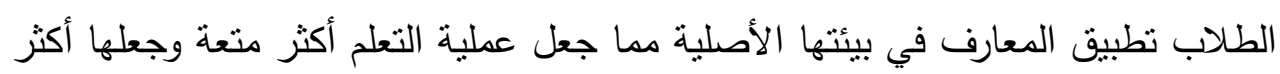
دافعية وساعد على انخراط الطلاب في عمليات التعلم، فالتعلم القائم على التكنولوجيا يعزز العصر الرقمي والممارسات التعليمية ويساعد الطلاب في استكثاف استخدام تكنولوجيا الطائرات بدون طيار في التعليم (Carnahan, 2016). لقد استخدمت الطائرات بدون طيار كأداة في تعزيز فعالية عمليات التعليم والتعلم

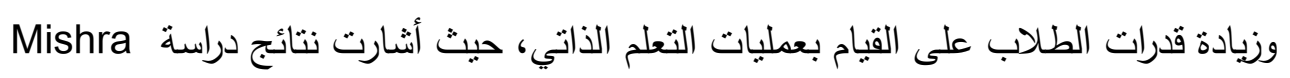
(2016) Koehler (أن دمج التكنولوجيا الحديثة في التعليم سوف بطرح الكثير من بن

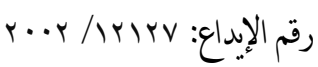

E-ISSN : $\ \wedge \cdot 0-r \wedge \circ \varepsilon$ https://ncerd.journals.ekb.eg بملة البحث التربوي:

ISSN: $\cdot \wedge \Lambda \mu-17 \Lambda V$ 
إسهامات بعض بجالات الاقتصاد الرقمي في رقمنة التعليم الفني من وجهة تظر الخبراء

التساؤلات التي تحتاج إلى أجوبة من جانب المعلمين حتى المتمرسين منهم سوف يجدون

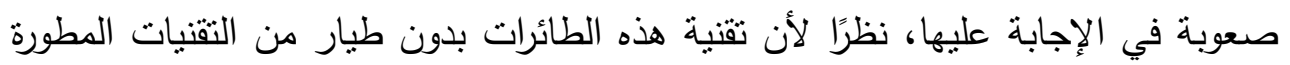

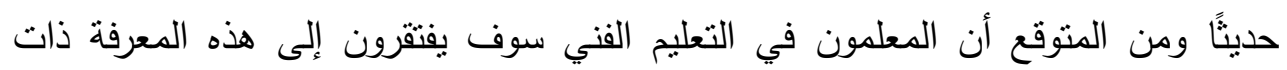
الصلة بهذه التكنولوجيا، لتحسين فعاليتهم في التدريس داخل الفصول الدراسية، لذا يتزايد الطلب يومًا بعد يوم على ضرورة تدريب المعلمين في هذه الدجال لتعرف احتباجات تدريب

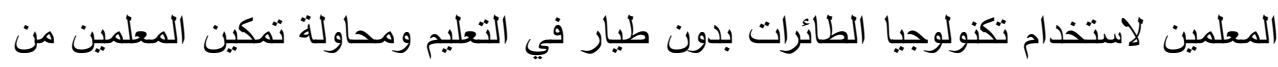
دمج تكنولوجيا الطائرات بدون طيار بشكل فعال في تعليمهم.

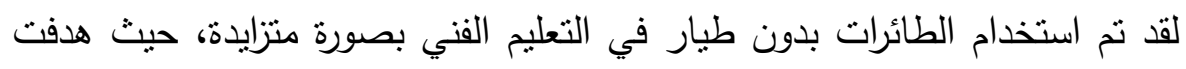
دراسة (2019) Ng,\& Cheng إلى تقيبم استعدادات المعلمين واحتياجات المندربين للتدريب على استخدام تكنولوجيا الطائرات بدون طيار في عمليات التدريس حيث تعزز هذه التكنولوجيات الحديثة من استخدام طرائق، وممارسات جديدة في التعليم، وكثفت فئن نتائج الدراسة عن وجود كفاءات كافية لدى الطلاب لإتقان المهارات والمعارف التكنولوجية

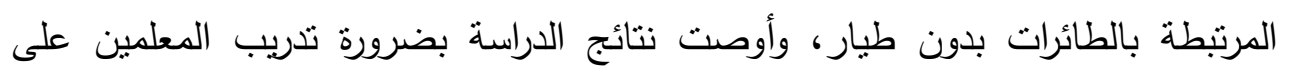

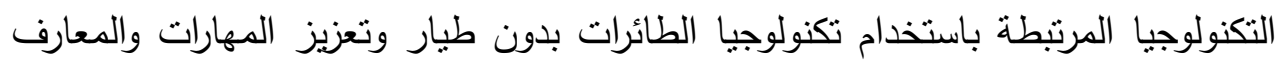

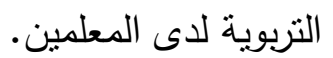

وأثنارت دراسة (2015) Preble إلى أن تقنية الطائرات بدون طيار قد ظهرت في

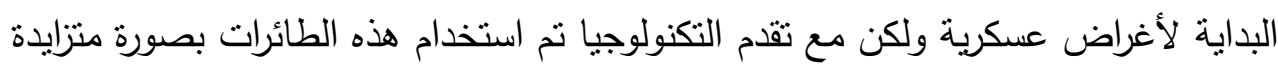
لأغراض مختلفة في حياتتا اليومية، حيث بدأت الحكومات والمنظمات والألفات لأفراد في استغلال

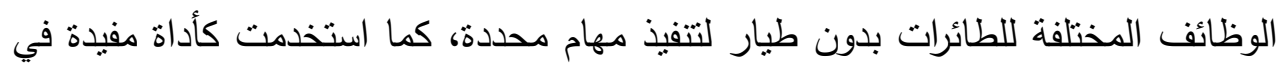

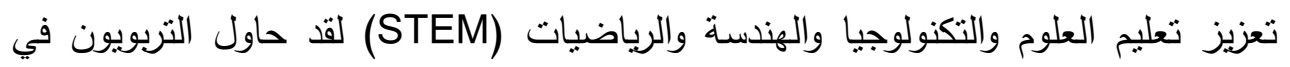

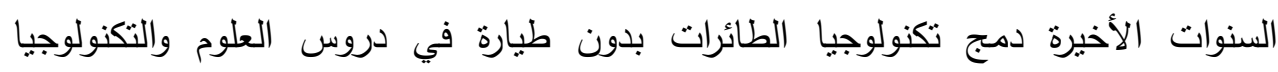

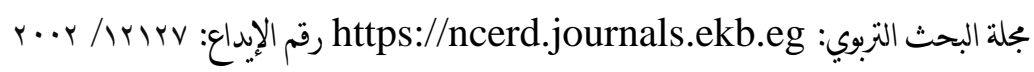

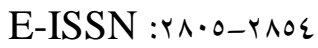

ISSN: $\cdot \wedge \Lambda \mu-I T \Lambda V$ 
والهندسة والرياضيات (Petrinjak, 2016). ومع ذلك لا يزال استخدام تكنولوجيا الطائرات

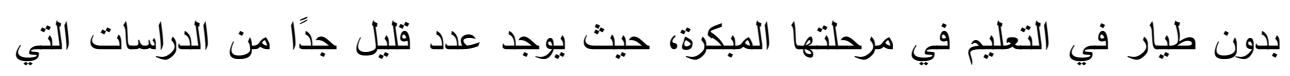
تمت في هذا المجال والتي كثفت عن حاجة المعلمين في التعليم الفني إلى التدريب على هلى هذه التقنيات الحديثة حتى يمكنه تعليم الطلاب بسهولة ويسر في هذا المجال.

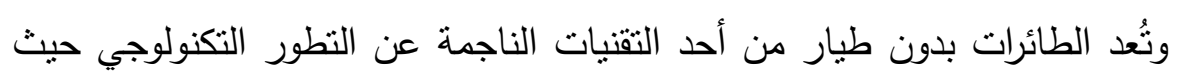
هدفت دراسة (2015) Stijn Poslema تعرف استخدامات الطائرات بدون طيار في الصحافة، وتوصلت نتائج الدراسة إلى استخدام الطائرات بدون طبار في الصحافة لإعداد تقارير كاملة ودقيقة، وتوسيع إمكانية الصحافة الاستقصائية، وإثراء إنتاجات الصحافة،

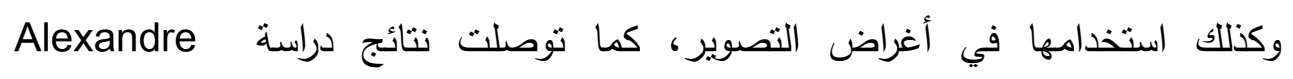

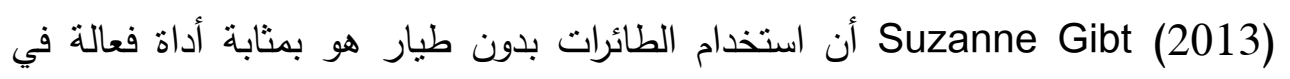
جمع الأخبار، وهي من الأدوات المهمة في غرف الأخبار، وفي حفظ وإدارة النظم البيئية

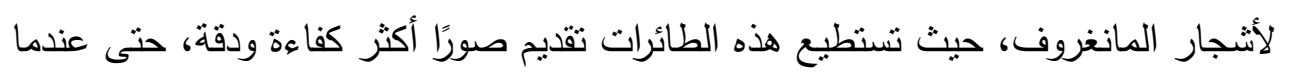

تكون السماء ملبدة بالغيوم(Cruz Silva, 2016).

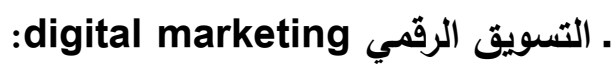

تطورت عمليات السويق الرقمي في السنوات الأخيرة بسرعة كبيرة نظرًا للتطورات المنسارعة في مجال تكنولوجيا المعلومات والاتصالات، والتي أسهمت في زيادة أعداد

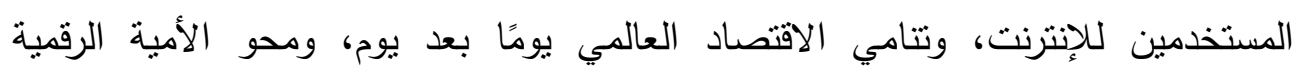

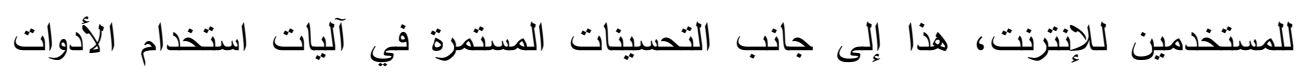

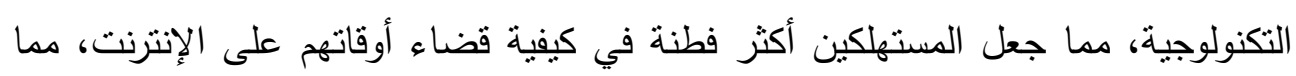
ساعد في إيجاد مجموعة من الطرائق الإبداعية الفعالة التي يمكن أن يستخدمها العملاء في التعامل مع الإنترنت (Get craft, 2017).

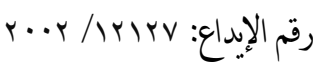

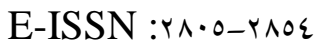

https://ncerd.journals.ekb.eg بلة البحث التربوي:

ISSN: $\cdot \wedge \Lambda \mu-I 7 \Lambda V$ 
إسهامات بعض بجالات الاقتصاد الرقمي في رقمنة التعليم الفني من وجهة تظر الخبراء

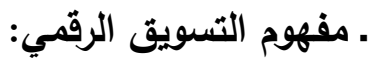

تنبأ نوفلر Toffler بعد الموجة الثالثة بتفكيك مجتمعات ما بعد الصناعة، والآن وبعد ثلاثة عقود لا تزال نهاية التنسويق غير وشيكة، على الرغم من اقتراح Kotler ضرورة

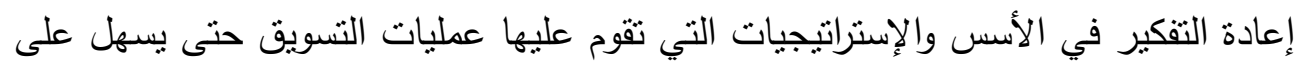

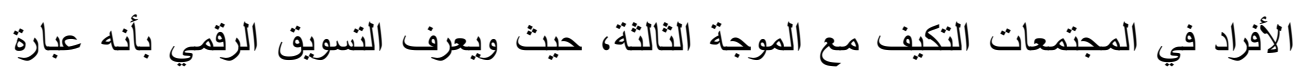

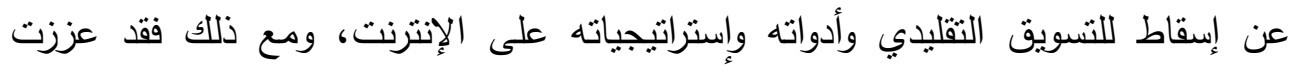

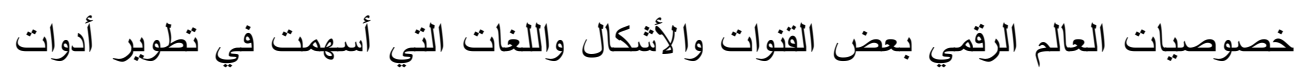

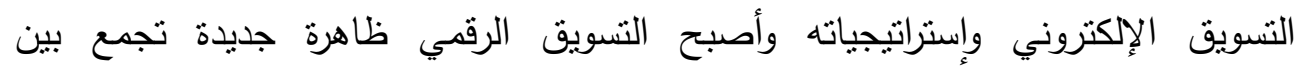

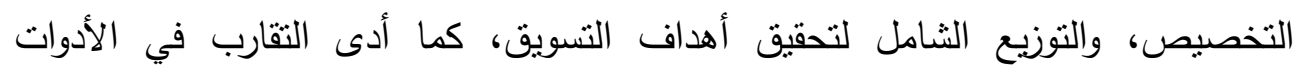

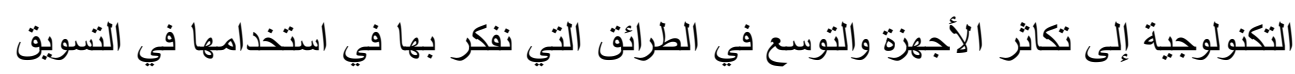

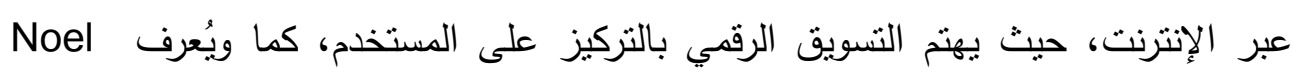

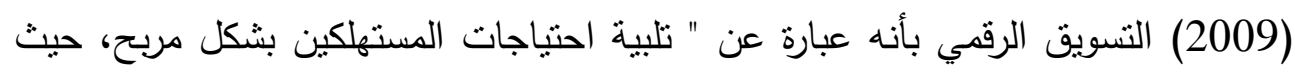

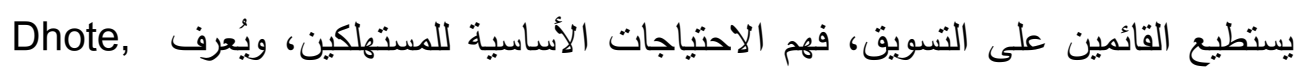

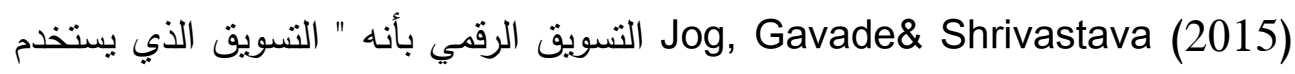

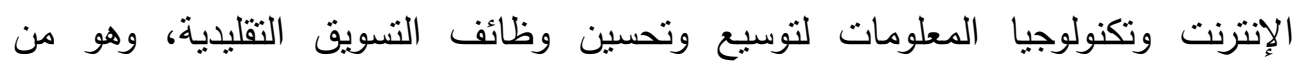

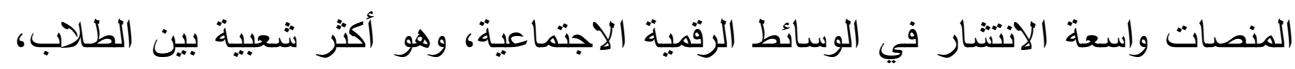

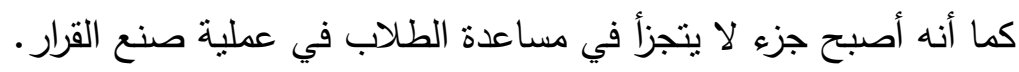
(WOODCO, 2013;Stoke, 2013; Pride\& Ferrel, كما عرفت دراسات (2016 التسويق الرقمي بأنه عبارة عن إستراتيجية التسويق التي ينم توظيفها باستخدام

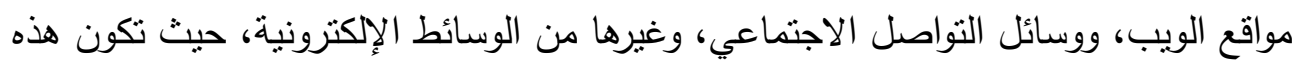

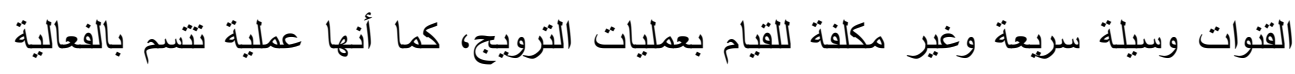

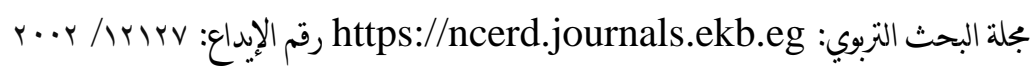

E-ISSN :Y^・0-Y^O\&

ISSN: $\cdot \wedge \Lambda \uparrow-17 N V$ 
واختصار المسافات والأوقات، وأصبحت من أهم الأساليب الحياتية القابلة للتغيير بصورة مستمرة تبعًا لتغير أنماط الحياة في المجتمع، وتبعًا للتغيرات السريعة الناجمة عن التطورات والتهات التهات التكنولوجية.

\section{ـ أهمية تعليم الطلاب في التعليم القني للتسويق الرقمي:}

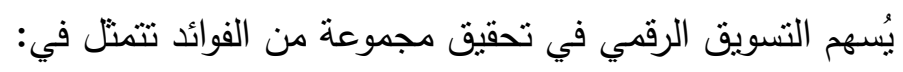

1. زيادة وعي الطلاب في التعليم الفني بأهمية تعرف آليات ممارسة التسويق الرقمي.

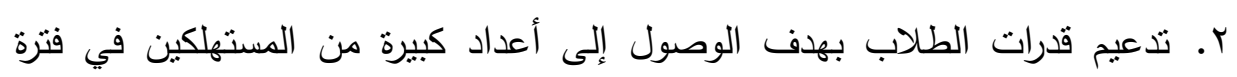
زمنية قصبرة.

r. تعلم الطلاب أن التسويق الرقمي يسهم في اختصار المسافات وخفض التكلفة مما

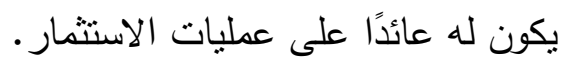
ع. تعريف الطلاب بأن التسويق الرقمي يسهم في تقديم الخدمات بصورة جذابة وموسعة. هـ اخبار الطلاب أن التسويق الرقمي لديه القدرة على مواكبة أحدث الاتجاهات العالمية الحديثة في التسويق. 7. تدعيم قدرات الطلاب على التسويق الرقمي من خلال التدريب على آليات التواصل السريع بين مقدمي الخدمة والمستهلكين، ومن خلال وجود منصة اجتماعية تقدم معلومات جيدة للمستهلكين (Kusumawati, 2019).

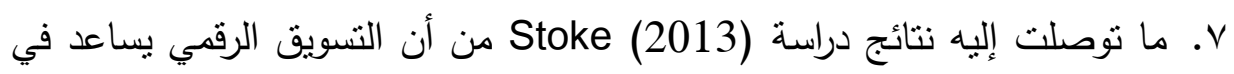

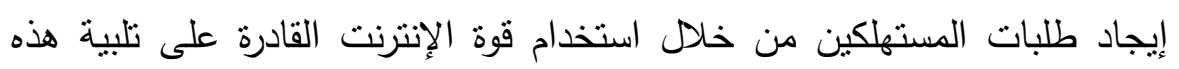
الطلبات بطرائق مبتكرة وبطرائق أكثر إبداعًا. 
إسهامات بصض بجالات الاقتصاد الرقمي في رقمنة التعليم الفني من وجهة نظر الخبراء

^. ما أكدت عليه نتائج دراسة Martin's من أن السويق الرقمي قد طرأ عليه

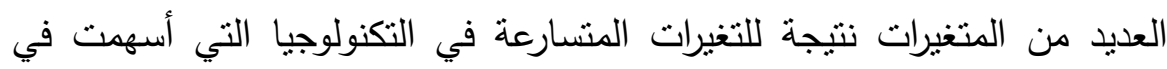

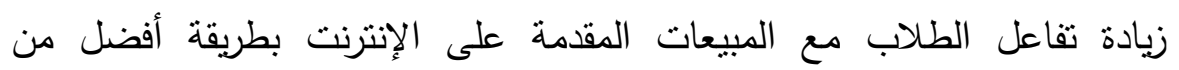
المبيعات المقدمة بالطرائق التقليدية.

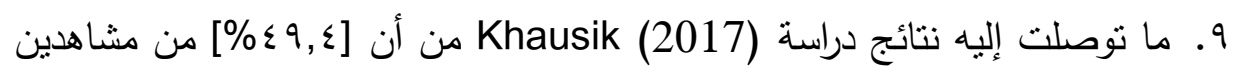

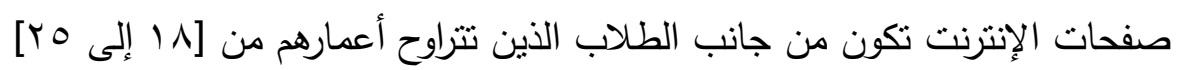

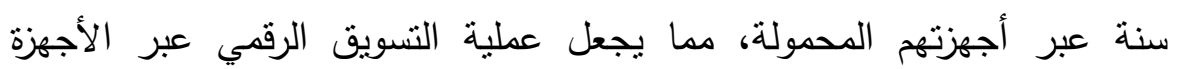
المحمولة من الأمور بالغة الأهمية.

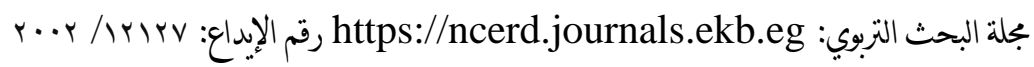

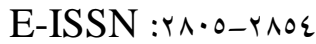
ISSN: $\cdot \wedge \Lambda \mu-I T A V$ 


\section{يوصف التسويق الرقمي بأنه تسويق:}

1. أكثر قابلية للقياس، إلى جانب أنه متواجد في كل مكان، ويمكن التفاعل معه، ويمكن تطويره وبناء علامات تجارية على الويب والعمل على تحديثاتها بصورة مستمرة.

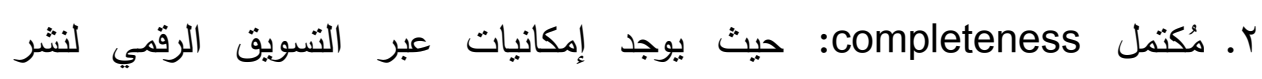
المعلومات من خلال روابط المستهلكين. r. سهل الاستخدام usability: حيث يمكن أن يتم عبر منصات رقمية بسيطة وسهلة الاستخدام مما يسمح بتعدد الأنشطة التجارية المستخدمة. ع. قائم على التفاعل interactivity: حيث يسمح هذا النمط من التسويق بإقامة علاقات طويلة الأمد مع الجماهير، حيث يوفر الإنترنت إمكانية وجود محادثة بين البائع والمشتري.

ه. قائم على التواصل البصري visual communication: حيث يقوم المسوق بعرض المنتجات باستخدام أدوات مختلفة تعتمد على الصور والفيديوهات وهي طريقة جذابة بهدف الوصول إلى الجماهير مما يزيد من نسب المشاركة، وبالتالي نسب المبيعات. 7 ا. يتسم بوجود الإعلانات المناسبة relevant advertising، وتتميز هذه الإعلانات بسهولة التقسيم والتنسيق والعمل من خلال الإنترنت يسهم في زيادة الإنتاج إلى الحد الإعدات التحكمي نظرًا للإعلانات التي يتمتع بها المنتج والتي تزيده جاذبية.

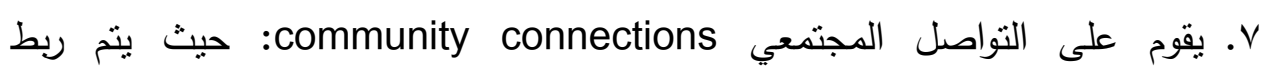
المؤسسات بالجماهير والمستخدمين، وهذا في حد ذاته يُسهر في تحسين خبرات المستخدمين وتعزيز علاقاتهم بالمنتج.

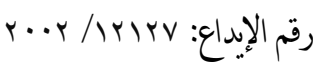

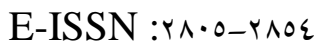

https://ncerd.journals.ekb.eg بلة البحث التربوي:

ISSN: • ANץ-I TAV 
إسهامات بعض بجالات الاقتصاد الرقي في رقمنة التعلم الفني من وجهة ظظر الخبراء

^. لديه القدرة على قياس المخرجات measuring output: حيث تحتل المنصات

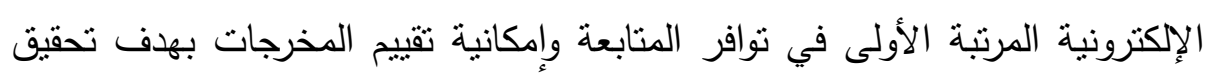

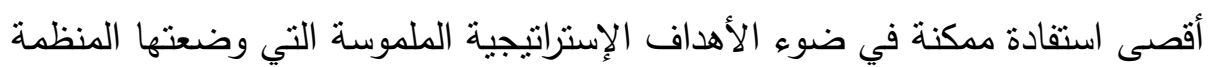
لنفسها (Pineiro-Otero \& Martinez-Rolan, 2016).

\section{المحور الثاني: الرقمنة في التعليم الفني: أولأ: مفهوم الرقمنة في التعليم الفني:}

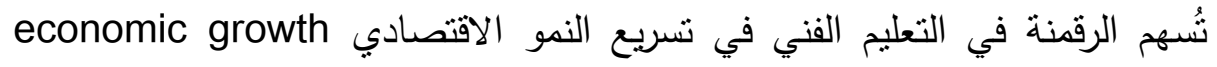

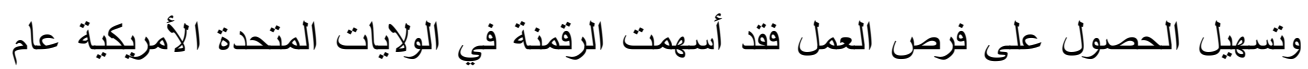

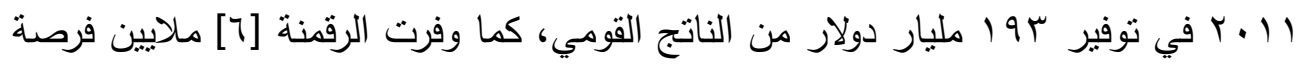
عمل، وأثشارت الأدبيات إلى أن الرقمنة لها تأثيرات إيجابية على جميع القالى القطاعات الإنتاجية

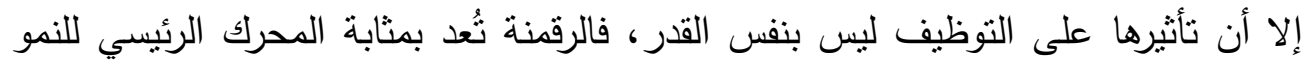

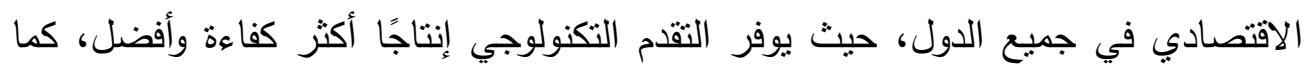
يوفر التقام التكنولوجي خدمات فنبة أفضل وأكثر .

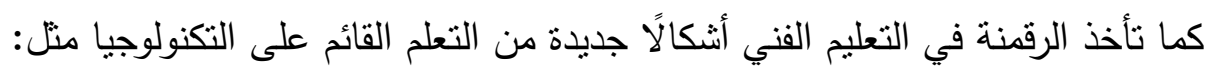

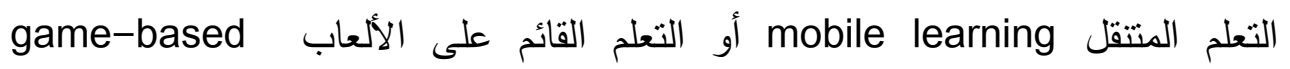
learning

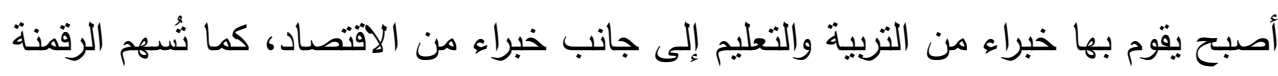

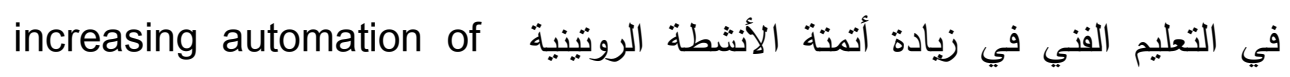
routine based activities المعقدة (Busse, Lange \& Schumann, 2019).

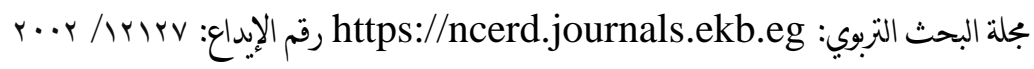

E-ISSN :Y^・0-Y^O\&

ISSN: $\cdot \wedge \Lambda \uparrow-17 N V$ 
وأثنارت دراسة (2020) Schmidt, et al إلى أن الرقمنة في التعليم الفني لا تؤثر في حياتتا اليومية فحسب وإنما تؤثر في سير العمل في القطاعات الفنية والحرفية وأنها تتطلب الكثير من الجهد للحفاظ على عمليات التحديث والتغلب على الروتين اليومي، وهذا يتطلب قيام التعليم الفني بتزوبد الطلاب بالمهارات الجديدة التي ينطلبها سوق العمل والقوى

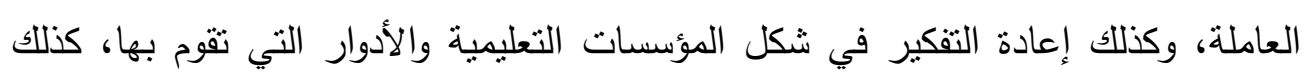
تعرف طريقة أداء المعلمين والمدربين، وتصميم المناهج الدراسية والدورات التدريبية، بهدف سد الفجوة الموجودة بين النظرية والتطبيق، والعمل على تدريب الطلاب على أليات استخدام الأدوات الرقمية بكفاءة، وتدعيم قدراتهم على التكيف مع العمليات التقليدية في التعلم.

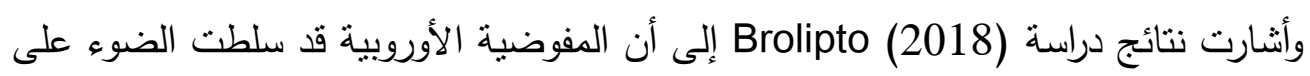
تعرف تأثنرات الرقمنة في التعليم الفني، وتوصلت إلى أن [ـ9\%] من الوظائف اليوم تتطلب

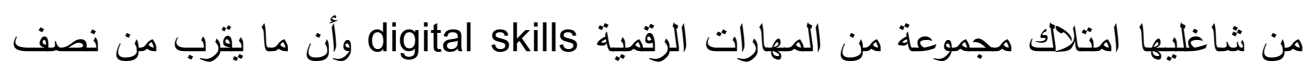

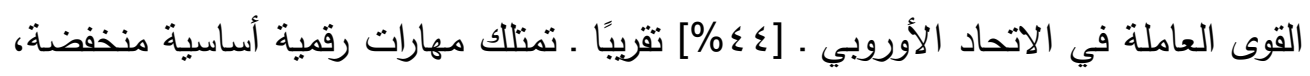
كما أثنارت إلى وجود [Yr\%] من القوى العاملة لا يمتلكون مهارات رقمية على الإطلاق.

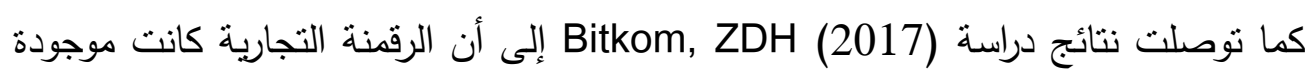
بنسبة [11\%] من المشاركين، كما كثف أكثر من نصف المشاركين في الدراسة عن وجود صعوبات وتحديات كبيرة في عملية التحول نحو الرقمنة، كما كثف أكثر من ثلثي العينة افتقارهم إلى محو الأمية الرقمية lock of digital literacy والتي يُعد من أكبر العقبات التي تواجه8م. ثانيًا: القوائد الاقتصادية للرقمنة في التعليم القني:

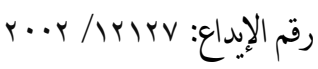

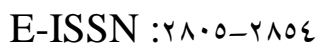

https://ncerd.journals.ekb.eg بلة البحث التربوي:

ISSN: $\cdot \wedge \wedge \mu-I T \wedge V$ 
إسهامات بعض بجالات الاقتصاد الرقمي في رقمنة التعليم الفني من وجهة تظر الخبراء

يعتبر التعليم الفني هو قلب الاقتصاد الرقمي، حيث تسهم الرقمنة في التعليم الفني في

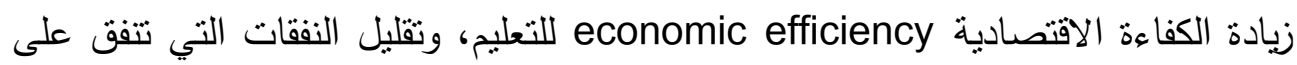
مؤسسات التعليم التقليدية من خلال: ا. القابلية للتشغيل البيني interoperability: حيث تسمح الأنظمة الإلكترونية الحديثة في إحداث التواصل بين البشر والمصانع الذكية smart factories، فالقابلية للتشغيل تعني القدرة على استغلال الأنظمة والعلميات لتبادل البيانات والمعلومات، والتواصل فيما بينهم لتعزيز الكفاءات أو الجدارات. r. المحاكاة الافتراضية virtualization: حيث يتم إنشاء نسخة افتراضية من المصنع الأكي عن طريق ربط البيانات المرتبطة بالمستشعر sensor data بالمصنع لأنساء الافتراضي. r. اللامركزية decentralization: حيث تتمتع الأنظمة الإكترونية الفيزيائية بالقدرة على اتخاذ القرارات بنفسها والإنتاج محليًا بفضل وجود تقنيات مثل الطباعة ثناثية الأبعاد.

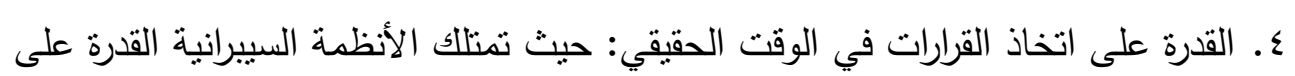
جمع البيانات وتحليلها وتقديم الرؤى المشتقة من عمليات التحليل بصورة فورية.

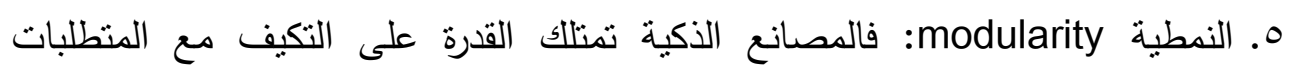
المتغيرة عن طريق الاستبدال أو التوسع في الوحدات التي تتضمنها هذه المصانع. 7. تحسين الإدارة في العملية التعليمية.

V. رفع مستوى أجور المعلمين والمتخصصين في إعداد المصادر التعليمية الإكترونية. ^. الحد من القيود المرتبطة بالملكية نتيجة لانخفاض تكاليف الطلاب المرتبطة بشراء الحاجات والمطبوعات والسفر والتتقلات.

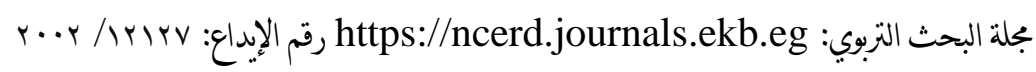

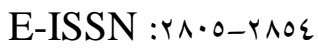

ISSN: $\cdot \wedge \Lambda \mu-I T \Lambda V$ 
9. تزويد بعض الفئات من الطلاب بالخدمات التعليمية، والتي يصعب عليهم الحصول

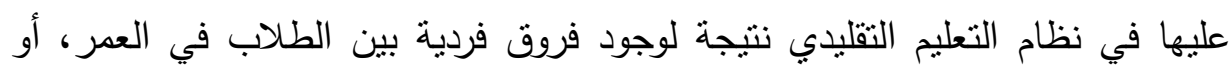
الجسم أو الفوارق الاجتماعية أو الجغرافية.

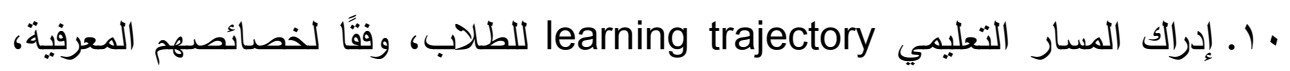

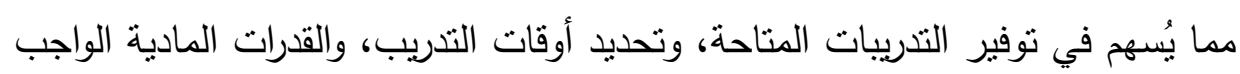

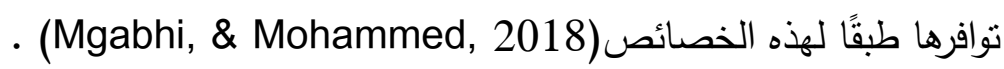
الـ الحسين الجودة في العملية التعليمية بصفة عامة فإدخال التكنولوجيا سوف يصحبه

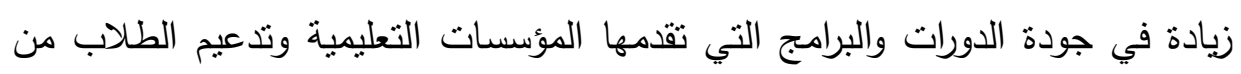
خلال عرض المواد التعليمية بطريقة شيقة وتفاعلية ومفيدة. r ا ـ تطوير المفاهيم التربوية الجديدة ونماذج التدريس، حيث يتم التركيز على المتعلم بدلًا من المعلم، والتركيز على الخصائص الفردية للطلاب في التعليم. با ـ الانتقال إلى النموذج المفتوح open model في التعليم والذي يُسهم في تتفيذ مفهوم

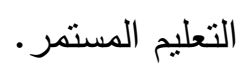
ع ا ـ توفير الوقت saves time، وخفض التكاليف reduced costs، والتقليل من حواجز الدخول، وتكوين بيانات مهمة يمكن أن ثقدم رؤى جديدة وتمكن الناس من العمل من المنزل enables people to work from home. ثالثًا: العوامل المؤثرة في رقمنة التعليم القني: وأثنارت دراسة (2019) Busse, Lange \& Schumann إلى وجود ثلاثة عوامل مؤثرة في عمليات الرقمنة في التعليم الفني مثل: العوامل المرتبطة بالفرد، والعوامل المرتبطة بالتقنيات، والعوامل المرتبطة بالبيئة وفيما يلي سوف نوضئ فئح كل عامل من هذه العوامل: 
إسهامات بعض بجالات الاقتصاد الرقمي في رقمنة التعليم الفني من وجهة تظر الخبراء

ا. العوامل المرتبطة بالفرد: وهي تلك العوامل التي تصف كفاءات وخبرات الأفراد، وخصائصهم الموضوعية والذاتية مثل: تعرف العوامل والسمات المعرفية، والوجدانية للأفراد والتي قد تؤثر في طريقة تكيفهم مع الرقمنة وتفاعلهم معها.

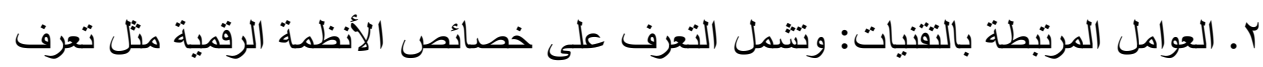

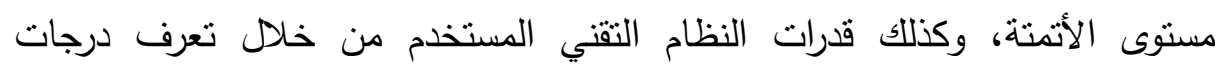

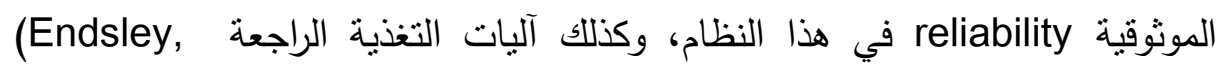
.2017)

r. العوامل المرتبطة بالبيئة: وهي تللك العوامل التي تصف بيئة العمل التي يعمل أو يدرس فيها الطلاب وهذا يتطلب تعرف خصائص المهمة مثل تعرف نوعية أو

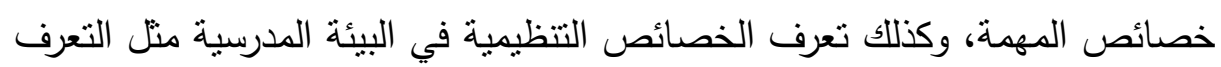

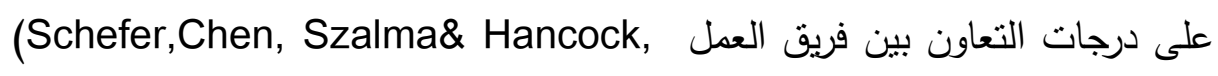

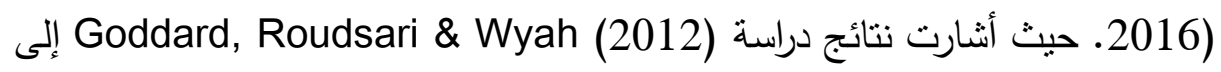
أن العوامل المرتبطة بالتقنيات، وبالبيئة الددرسية هي عوامل يمكن للطلاب التكيف

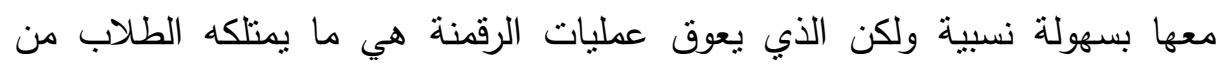

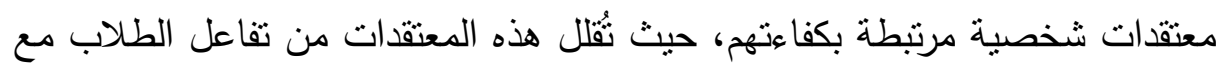

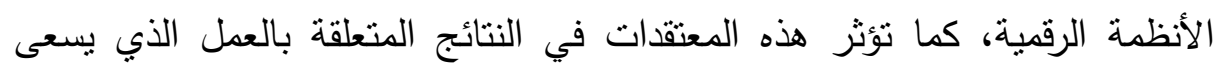
الطلاب إلى تحقيقه.

رابعًا: قياس الكفاءة الرقمية لطلاب التعليم الفني:

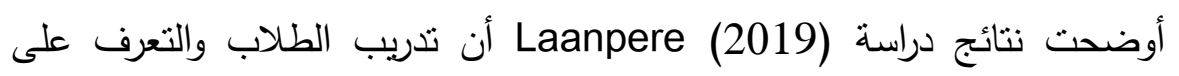
معتقداتهم الثخصية المرتبطة بكفاءتهم في استخدام التقنيات الحديثة يمكن أن يُحسن ويزيد

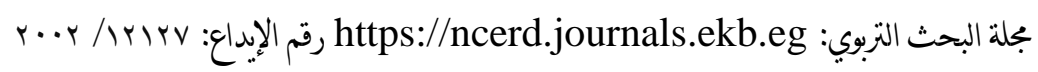

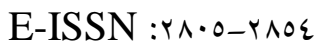

ISSN: $\cdot \wedge \Lambda \mu-I T \Lambda V$ 
digital نفاعل الطلاب مع الأنظمة الرقمية، من خلال تعرف الكفاءة الرقمية competence ا. معرفة المعلومات والبيانات information and data literacy وتتمنل في قدرات الطلاب على القيام بعمليات التصفح browsing والبحث searching، وتتقية البيانات digital content، والمعلومات المرتبطة بالمحتوى الرقمي وكذلك قدرات الطلاب على القيام بعمليات تقييم البيانات والمعلومات في المحتوى بهى الرقمي، وكذللك كيفية إدارة البيانات والمعلومات في المحتوى الرقمي.

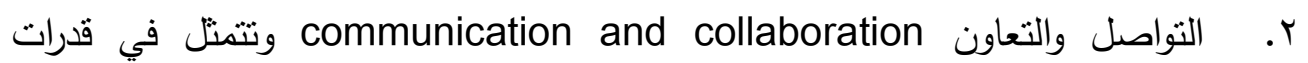
الطلاب على التفاعل مع التقنيات الرقمية والمشاركة والانخراط معها، والتعاون مع ونع

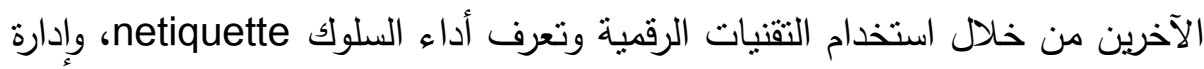
البيانات الرقمية. r. إنشاء المحتوى الرقمي digital content creation وتتمثل في قدرات الطلاب على تطوير وتتمية المحتوى الرقمي وتحقيق التكامل والتوسع في المحتوى الرقمي، وتعرف

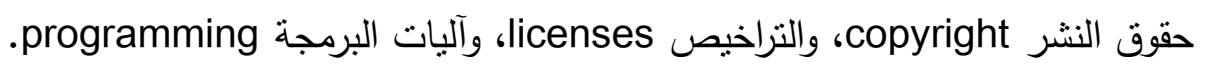

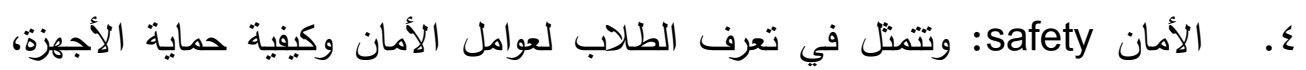
وحماية البيانات الشخصية، وحماية الخصوصية، وحماية الصحة وتحقيق الرفاهية والطمأنينة، وحماية البيئة. 0. حل المشكلات problem solving: وتتمثل في قدرات الطلاب على حل المشكلات التقنية التي تواجهرم، والقدرة على تحديد الاحتياجات، والاستجابات التقنية، وكيفية تحديد الفجوات في الكفاءة الرقمية عن طريق استخدام أدوات الرقمنة الإلكترونية مثل ولت ولثيل

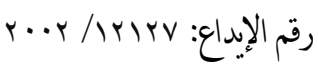

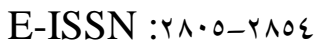

https://ncerd.journals.ekb.eg بجلة البحث التربوي:

ISSN: $\cdot \wedge \Lambda \mu-17 \Lambda V$ 
إسهامات بعض بجالات الاقتصاد الرقمي في رقمنة التعليم الفني من وجهة تظر الخبراء

الحاسوب، والإنترنت، والهاتف الذكي، والماسح الضوئي، والكاميرا الرقمية، وجهاز العرض، والطابعة..... إلخ) (Carretero, Vuorikari \& Punie, 2017) ويرى (2014) Stuart أن انتقال التعليم إلى التعليم الرقمي يُعد نقطة تحول في تاريخ

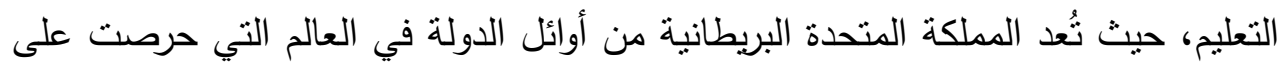

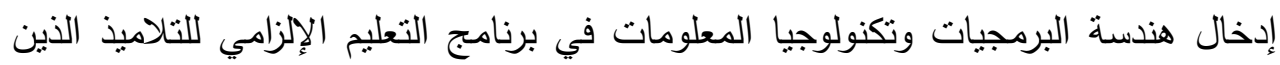

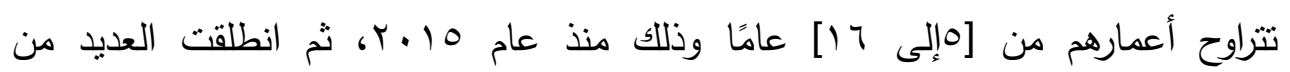
المبادرات والتي كانت تهدف إلى دمج التكنولوجيا في أنشطة المؤسسات التعليمية في الاتحاد الأوروبي.

لقد أظهرت نتائج العديد من الأدبيات وجود تأثيرات ملحوظة لاستخدام تكنولوجيا

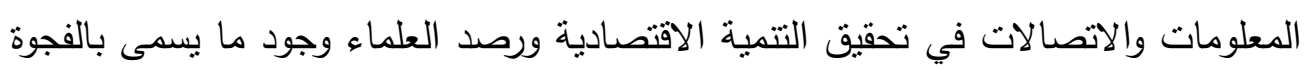

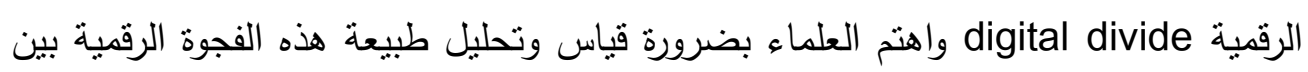
الدول (Machekhina, 2017).

لقد ألقت الرقمنة في التعليم بظلالها على منطلبات على مهارات العمل، والظروف

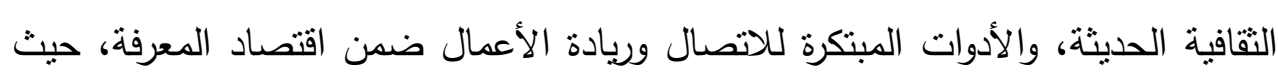

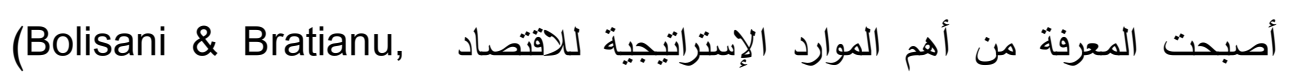

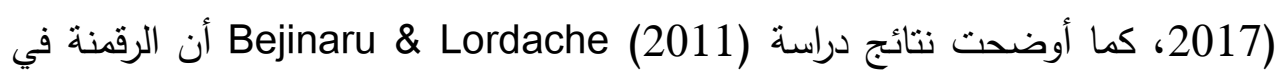

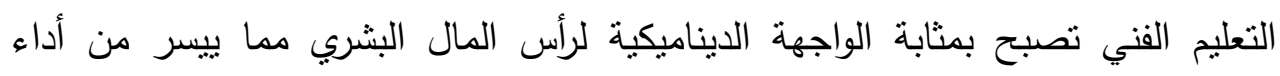

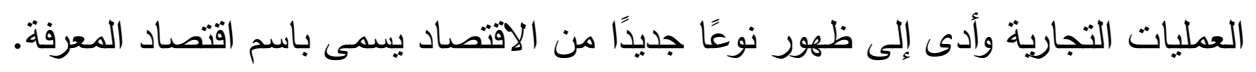

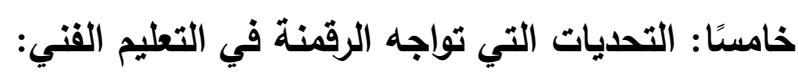
تعمل الرقمنة على إعادة نتكيل الوظائف على مستوى العالم باستخدام التقنيات التهات

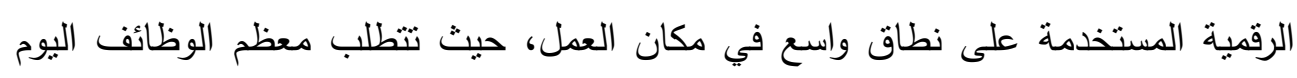

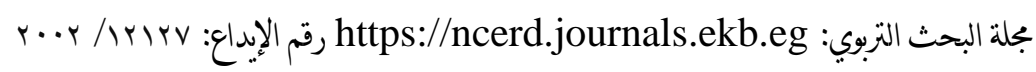

E-ISSN :Y^・0-Y^O\&

ISSN: $\cdot \wedge \Lambda \uparrow-17 N V$ 
مهارات رقمية أساسية مثل القدرة على التواصل عن طريق البريد الإكتروني، وسائل التواصل الاجتماعي social media، وإنثاء المستندات الرقمية digital documents،

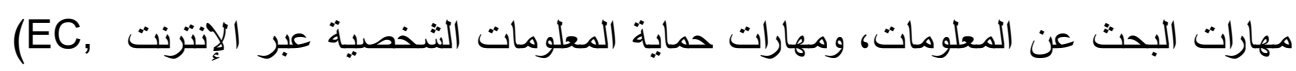

كما دعت الرقمنة في التعليم الفني إلى وجود حاجة منزايدة للتنريب على الثقنيات

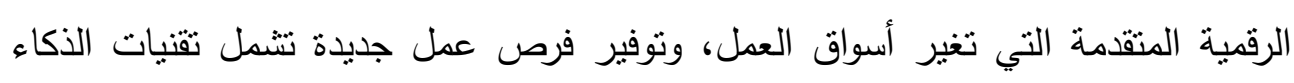

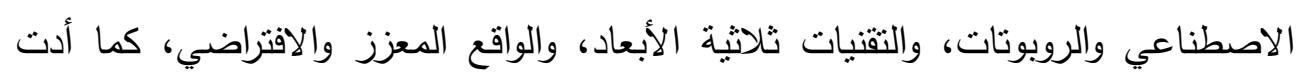

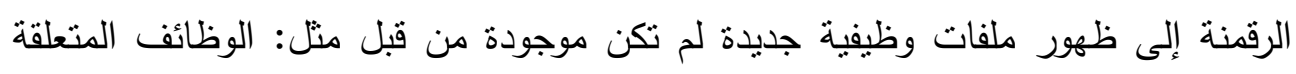

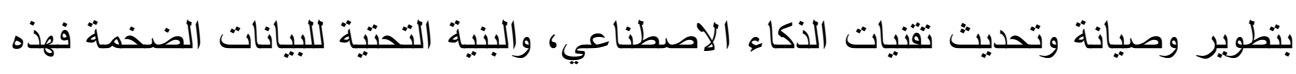
الوظائف من المتوقع لها أن تتمو وتتطور في المستقبل (EC, 2019).

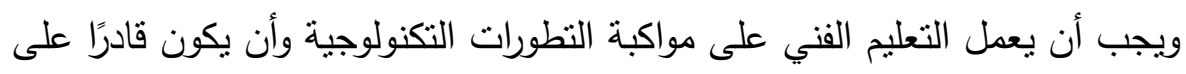

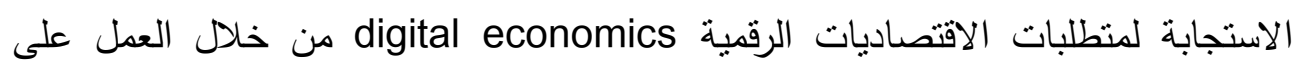

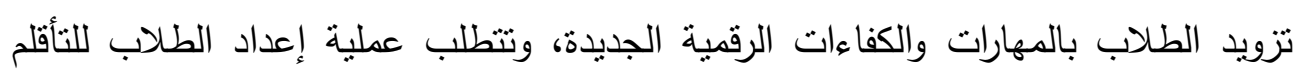

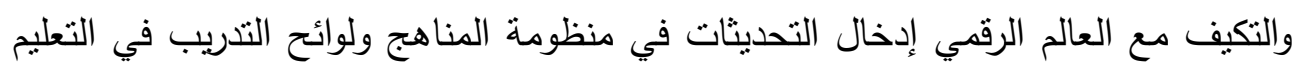

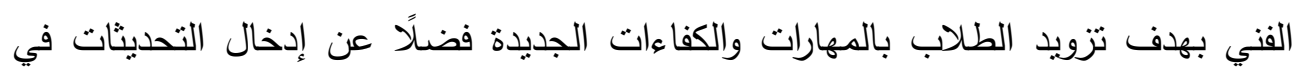

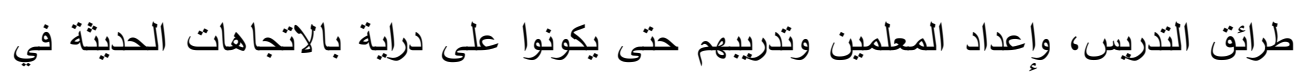

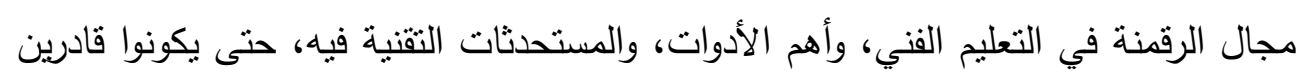

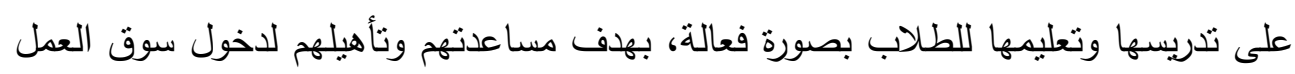

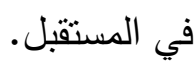


إسهامات بضض بجالات الاقتصاد الرقمي في رقمنة التعليم الفني من وجهة نظر الخبراء

ويُعد مشروع قنطرة التجديد والتعليم في التدريب والتعليم التقني والمهني Bridging innovation and Learning in TVET (BILT) الإستراتيجيات المتعلقة بالرقمنة في التعليم الفني: ا. التحديث الاستباقي للمناهج الدراسية في التعليم الفني واللوائح والقوانين المتعلقة بالتدريب بهدف مواكبة السرعة في النطورات الرقمية الجديدة. r. إقامة تعاون وثيق بين الثركات والمدارس من أجل معالجة اتجاهات الرقمنة بصورة أفضل، وضمان تطوير المهارات الرقمية للطلاب ذات الصلة. r. تدريب أعضاء هيئة التدريس في التعليم الفني والتدريب التقني والمهني على المهارات الرقمية وتزويدهم بالأدوات والمواد التعليمية المتطورة. ع. إعداد الطلاب لاستخدام التقنيات المتقدمة لجعل التعليم الفني جذابًا وملائمًا لاحتياجات سوق العمل.

فروض الاراسة:

الفرض الأول: " نوجد فروق دالة إحصائًًا عند مستوى [1 .,] في متوسطات استجابات الخبراء حول إسهامات بعض مجالات الاقتصاد الرقمي [إنترنت الأشياء] في رقمنة التعليم الفني ".

الفرض الثاني: "توجد فروق دالة إحصائيًا عند مستوى [1 +,] في متوسطات استجابات الخبراء حول إسهامات بعض مجالات الاقتصاد الرقمي [تكنولوجيا الطائرة بدون طيار] في رقمنة التعليم الفني ". الفرض الثالث: " توجد فروق دالة إحصائًا عند مستوى [1 .,] في متوسطات استجابات الخبراء حول إسهامات بعض مجالات الاقتصاد الرقمي [التسويق الرقمي] في رقمنة التعليم

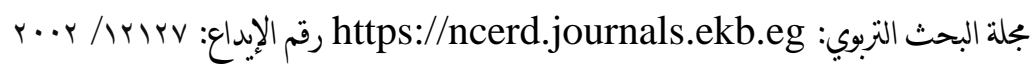

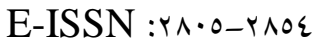

ISSN: $\cdot \Delta \Lambda \mu-I T \Lambda V$ 
إسهامات بصض بجالات الاقتصاد الرقي في رقمنة التعليم الفني من وجهة تظر الخبراء

\section{منهج الداسة وإجراءاتها:}

يتضمن منهج الدراسة، والأداة المستخدمة في جمع البيانات، وخطوات تصميمها، وحساب المعاملات الإحصائية [الصدق والثبات، والاتساق الداخلي]، والأسلوب الإحصائي

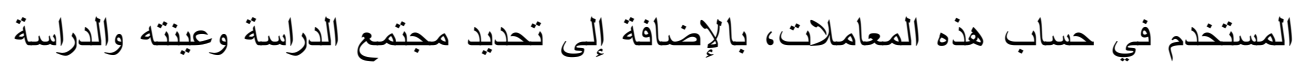
الاسنطلاعية والأساسية ويتضح ذلك فيما يلي: ـ منهج الدراسة: تهلف الاستبانة إلى قياس توجه الخبراء في الاقتصاد والتعليم الفني نحو تعرف وجهة نظرهم حول إسهامات بعض مجالات الاقتصاد الرقمي في رقمنة التعليم الفني، وفي سبيل ذلك تم استخدام المنهج الوصفي والتحليلي والدقارن.

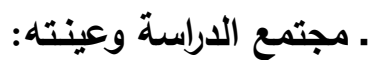

يتمنل مجتمع الدراسة في الخبراء حيث تم اختيارها من الجامعات ممنلة في كليات التجارة جامعة الزقازيق، والقاهرة، والمراكز البحثية، ممتلة في المركز القومي للبحوث التربوية

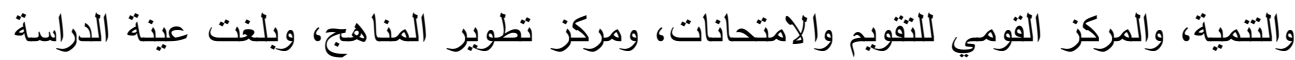

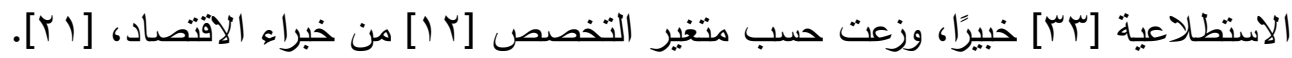
أما عينة الدراسة النهائية فتكونت من [19] من الخبراء في مجالي الاقتصاد والتعليم الفني، والجدول [1] يوضح توزيع العينة الاستطلاعية والنهائية حسب التخصص.

جدول [1]

توزيع أعداد العينة الاستطلاعية والنهائية وفقًا للتخصص"

\begin{tabular}{|c|c|c|c|}
\hline \multirow[t]{2}{*}{ الإجمالي } & \multicolumn{2}{|c|}{ التخصص } & \multirow[t]{2}{*}{ العينة } \\
\hline & خبراء التعليم الفني & خبراء الاقتصاد & \\
\hline$[r r]$ & {$\left[r_{1}\right)$} & {$[r]$} & الاستطلاعية \\
\hline [91] & [י] & [rol & النهائية \\
\hline
\end{tabular}

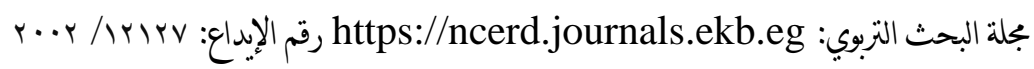

E-ISSN :YN・O-YNO\&

ISSN: $\cdot \wedge \wedge \mu-17 \wedge V$ 


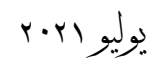

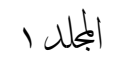
$\varepsilon \cdot$ sudl

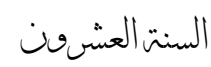

. أداة الدراسة:

مرت عملية إعداد أداة الدراسة بمجموعة من الخطوات هي: الإل

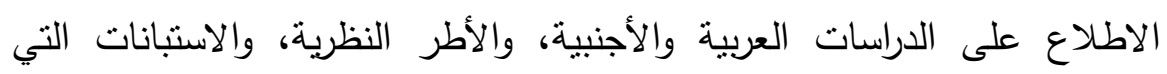

تنتاولت.

إعداد أداة الدراسة في صورتها الأولية.

عرض الأداة في صورتها الأولية على الدحكمين، وتكونت أداة الدراسة من ثلاثة إلثا

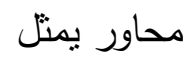

المحور الأول: ويتكون هذا المحور من [• [1] مفردات تقيس استطلاع رأي الخبراء

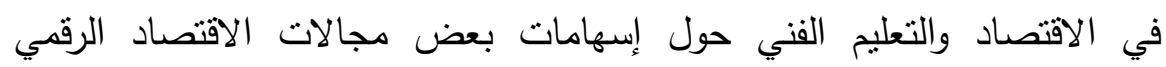

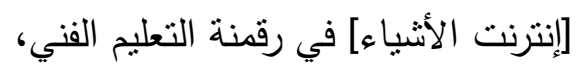

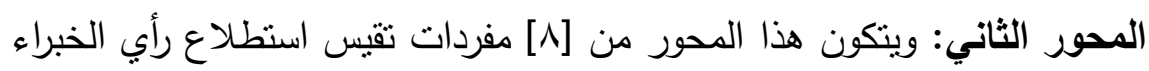

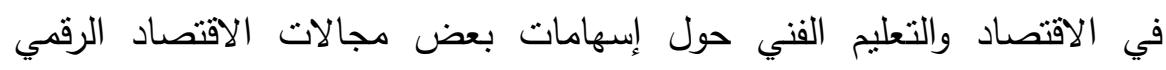

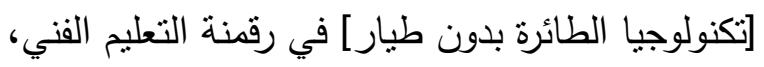

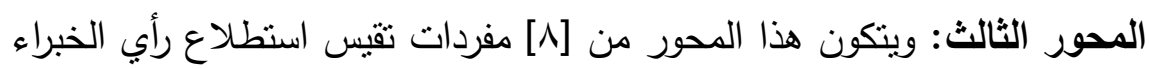

في الاقتصاد والتعليم الفني حول إسهامات بعض مجاتلات التات الاقتصاد الرقمي

[التسويق الرقمي] في رقمنة التعليم الفني ".

جدول [بال

" توزيع مفردات الأداة على محاور الاستبانة الثثلاثة "

\begin{tabular}{|c|c|c|c|}
\hline الإجمالي & المفردات & محاور الاستبانة & م \\
\hline$[1 \cdot]$ & [1 إلى . [1] & إنترنت الأثشياء & \\
\hline$[\wedge]$ & [1' إلى 11 ] & تكنولوجيا الطائرة بدون طيار & r \\
\hline$[\wedge]$ & [9 19 إلى & التسويق الرقمي & $r$ \\
\hline
\end{tabular}

بجلة البحث الزبوي:

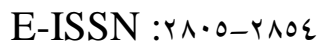

ISSN: $\cdot \wedge \wedge \uparrow-17 \Lambda V$ 
إسهامات بعض بجالات الاقتصاد الرقمي في رقمنة التعليم الفني من وجهة نظر الخبراء

$$
\text { الخصائص السيكو مترية للاستبانة: } 1 \text { ابوضح الجدول توزيع مفردات الاستبانة على أبعادها. }
$$

تم التحقق من صدق الأداة من خلال تعرف الصدق الظاهري للاستبانة، حيث تم عرضها في صورته الأولية على مجموعة من الأساتذة المتخصصين في مجال التربية تخصص مناهج وطرق التدريس وأصول تربية، وعلم نفس تربوي لإبداء الرأي في: دقة الصياغة اللغوية للمفردات، وملاءمة المفردات للبعد الذي تقيسه، وفي ضوه وآ آراء الأساتذة المحكمين، نم إعادة صياغة بعض العبارات بصورة أكثر وضوحًا، واتققوا على سلامة عبارات الاستبانة، من حيث تمثيل كل عبارة لمضمون البعد الذي تتنمي إليه.

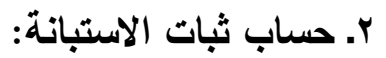

تم حساب ثبات الاستبانة عن طريق حساب معامل ألفا كرونباخ، وطريقة التجزئة النصفية، باستخدام معادلتي سبيرمان وبراون وجتمان:

\begin{tabular}{|c|c|c|c|}
\hline \multicolumn{3}{|c|}{ طرق الثبات } & \multirow{2}{*}{ 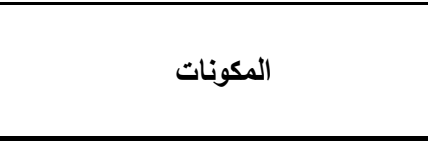 } \\
\hline جتمان & سبيرمان & ألفا & \\
\hline , ^IV & ,qrr &,$\wedge \circ 4$ & إنترنت الأشياء [IOT] \\
\hline , Аঙч & ,91. & , A Y & تكنولوجيا الطائرة بدون طيار] \\
\hline , А५ & ,qVr &, $9 \leq 9$ & النسويق الرقمي [DIM] \\
\hline ,vor & (94) & $\overline{s, \wedge \vee 1}$ & الارجة الكلية \\
\hline
\end{tabular}
جدول [ب]

طرق حساب الثبات بمعامل ألفا كرونباخ سبيرمان وجتمان للمكونات الفرعية "

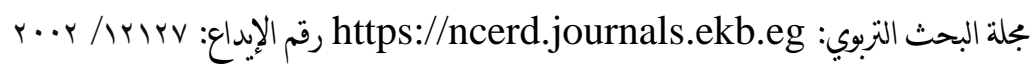

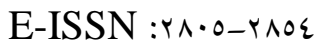

ISSN: $\cdot \Delta \Lambda \mu-I T \Lambda V$ 
يوضح جدول [r] حصول الاستبانة بمكونتها الفرعية على درجة مرتفعة من الثبات،

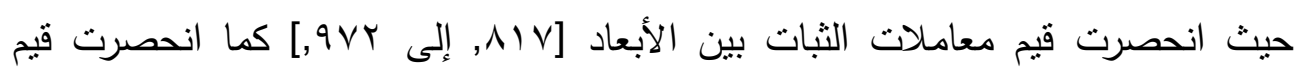

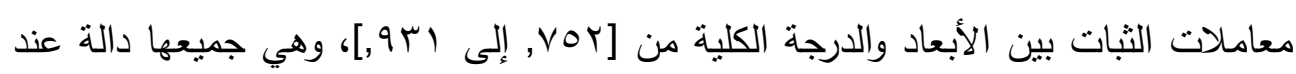

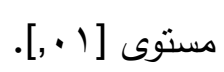

r. الاتساق الااخلي للاستبانة: وقد نم التحقق من ذلك بحساب معاملات الارتباط بين

$$
\text { المفردات مع الدرجة الكلية للبعد الذي تتنمي إليه: }
$$

\begin{tabular}{|c|c|c|c|c|c|}
\hline \multicolumn{2}{|c|}{ التسويق الرقمي } & \multicolumn{2}{|c|}{ تكنولوجيا الطائرة } & \multicolumn{2}{|c|}{ إنترنت الأثشياء } \\
\hline معاملات & المفردات & معاملات & المفردات & معاملات & المفردات \\
\hline$* *, O r v$ & Q19 & $* *, \leqslant \wedge 1$ & Q11 & $* *, 4 \wedge \mathrm{V}$ & Q1 \\
\hline$* *, \vee \backslash V$ & Q20 & $* *, \curlyvee \wedge \vee$ & Q12 & $* *, \vee 19$ & Q2 \\
\hline 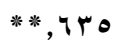 & Q21 & $* *, \vee \neg \varepsilon$ & Q13 & q * ז ז & Q3 \\
\hline$* *, 001$ & Q22 & $* *, \vee १ ৭$ & Q14 & **, Or & Q4 \\
\hline$* *, 7,9$ & Q23 & $* *, \vee r 4$ & Q15 & $* *, \uparrow \wedge 0$ & Q5 \\
\hline$* *, \leqslant \wedge 1$ & Q24 & **,ory & Q16 & $* *$ * $\{9$ Y & Q6 \\
\hline$* *, \leqslant \leqslant 4$ & Q25 & $* *, \leqslant 1 \wedge$ & Q17 & $* *, \Delta 91$ & Q7 \\
\hline$* *, \vee \leq$ & Q26 & **,rqo & Q18 & **, TY & Q8 \\
\hline & & & & $* *, 701$ & Q9 \\
\hline & & & & **\%, ¿ & Q10 \\
\hline
\end{tabular}

قيمة معاملات الارتباط بين المفردات مع الارجة الكلية للبعد الأي تنتمي إليه

[" [" دالة عند مستوى [ • , ,].

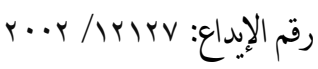

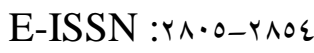

https://ncerd.journals.ekb.eg بلة البحث التربوي:

ISSN: $\cdot \wedge \wedge \mu-I T \wedge V$ 
إسهامات بعض بجالات الاقتصاد الرقمي في رقمنة التعليم الفني من وجهة تظر الخبراء

يوضح جدول [؛] أن جميع قيم معاملات ارتباط المفردات بالدرجة الكلية للمكون الذي

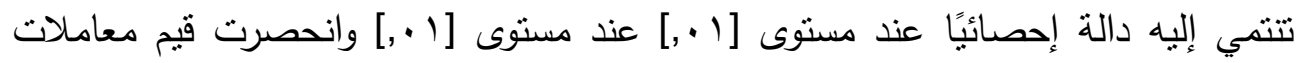

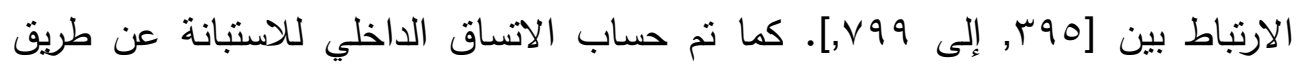
حساب معاملات الارتباط بين المكونات الفرعية والدرجة الكلية للاستبانة:

جدول [0]

معاملات الارتباط بين المكونات الفرعية للاستبانة، والدرجة الكلية له"

\begin{tabular}{|c|c|c|c|c|}
\hline اللارجة الكلية | & التسويق الرقمي & تكنولوجيا الطائرة & إنترنت الأثياء & المكونات \\
\hline & & & 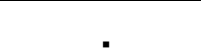 & إنتزنت الأثياء \\
\hline & & ${ }^{\circ}$ & $* *, V \Psi r$ & تكنولوجيا الطائرة | \\
\hline & - & $* *, \vee \backslash \wedge$ & $* *, V Y Y$ & |التسويق الرقمي | \\
\hline . & $* *$ * Arr & $* *, \wedge \diamond 0$ & $* *, १ \backslash \wedge$ & الدرجة الكلية \\
\hline
\end{tabular}

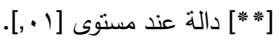

يوضح جدول [0] أن جميع قيم معاملات ارتباط المكونات بالدرجة الكلية للاستبانة

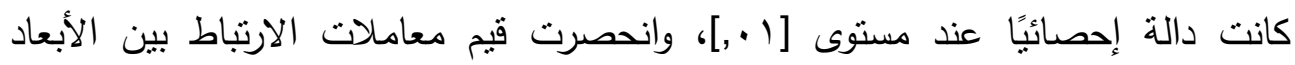

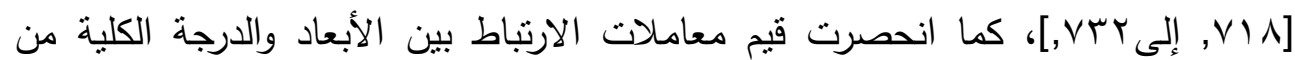

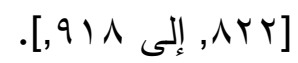

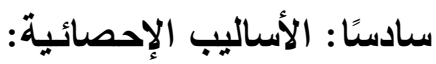

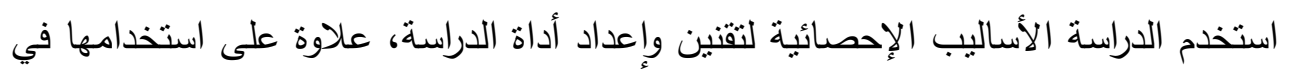
حساب صدق وثبات الأداة، وكنلك التحقق من الاتساق الداخلي للأداة، كما تم استخدام

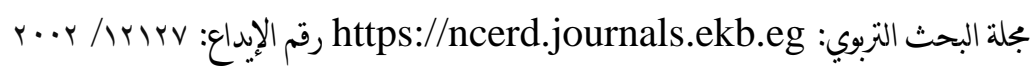

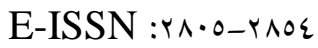

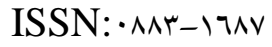


الأساليب الإحصائية التالية: معاملات الارتباط، المتوسطات الحسابية، والانحرافات

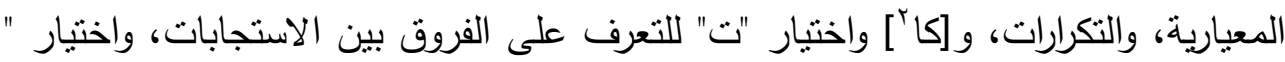

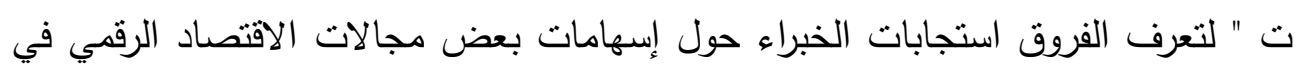
رقمنة التعليم الفني".

\section{نتائج الدراسة وهناقشتها وتفهيرها: التحقق من صحة الفرض الأول:}

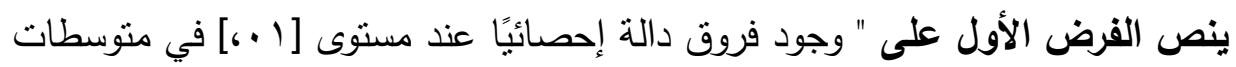
استجابات الخبراء حول إسهامات بعض مجالات الاقتصاد الرقمي [إنترنت الأثباء] في

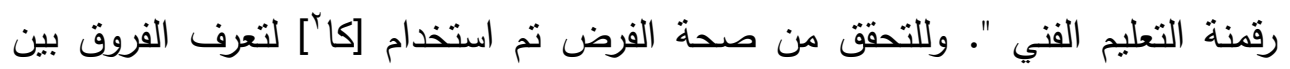
استجابات الخبراء حول إسهامات بعض مجالات الاقتصاد الرقمي [إنترنت الأشياء] في رقمنة التعليم الفني والموضحة بالجدول التالي: جدول [ب]

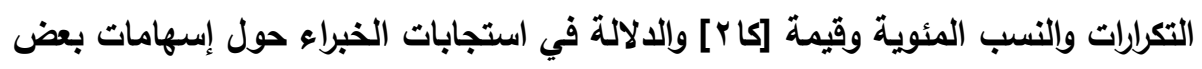

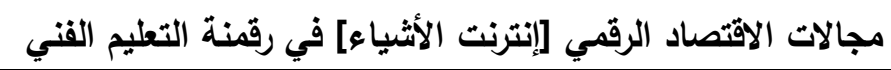

\begin{tabular}{|c|c|c|c|c|c|c|c|c|c|}
\hline \multirow[t]{3}{*}{ الدلالة } & rs & \multicolumn{2}{|c|}{ لا } & \multicolumn{2}{|c|}{ إلى حذ ما } & \multicolumn{2}{|c|}{ نعم } & \multirow[t]{2}{*}{ المفردات } & \multirow[t]{2}{*}{ م } \\
\hline & & $\%$ & ث & $\%$ & $ت$ & $\%$ & $ت$ & & \\
\hline & & & & & & & & 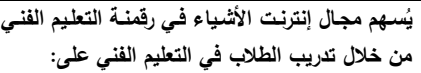 & أولُا \\
\hline, .1 & 90,1 & $\varepsilon, \varepsilon$ & $\varepsilon$ & $1 \leqslant, r$ & 14 & $\wedge, r$ & $\mathrm{~V} \varepsilon$ & آليات التحكم في جهاز معين & 1 \\
\hline,.+1 & $\leq r, \Lambda$ & $\mathrm{v}, \mathrm{v}$ & $v$ & $r \wedge, \uparrow$ & Y & $8 r, v$ & $\Delta \wedge$ & التواصل مع أجززة الحاسوب المختلفة & $r$ \\
\hline, .1 & 90,1 & $\varepsilon, \varepsilon$ & $\varepsilon$ & $1 \leqslant, r$ & ir & $\wedge, r$ & $v \varepsilon$ & استخدام الهواتف الذكية عبر الثبكة العالمية & $r$ \\
\hline, .1 & 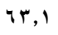 & I $\mathrm{r}, 1$ & 11 & $10, \varepsilon$ & $1 \varepsilon$ & $V Y, 0$ & 17 & كيفية التحرر من المكان الذين هم فيه & $\varepsilon$ \\
\hline, .1 & $7 \cdot, 1$ & 0,0 & $\bullet$ & $r \leq, r$ & r & $v \cdot, r$ & I & تحقيق التفاهم بين الأجهزة مع بعضها البعض & • \\
\hline
\end{tabular}

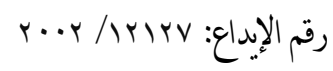

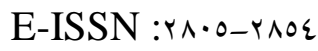

https://ncerd.journals.ekb.eg بجة البحث النربوي:

ISSN: $\cdot \wedge \wedge \mu-I T \wedge V$ 
إسهامات بضض بجالات الاقتصاد الرقمي في رقمنة التعليم الفني من وجهة نظر الخبراء

\begin{tabular}{|c|c|c|c|c|c|c|c|c|c|}
\hline \multirow[t]{2}{*}{ الدلالة } & \multirow[t]{2}{*}{ S's } & \multicolumn{2}{|c|}{$y$} & \multicolumn{2}{|c|}{ إلى حد ما } & \multicolumn{2}{|c|}{ ن ت نعم } & \multirow[t]{2}{*}{ المفردات } & \multirow[t]{2}{*}{ م } \\
\hline & & $\%$ & $ت$ & $\%$ & $ت$ & $\%$ & ث & & \\
\hline,+1 & $\bullet \wedge, \wedge$ & $\bullet, 0$ & • & $r \varepsilon, r$ & rr & $v \cdot, r$ & $7 \leq$ & التخاطب والاتصال عبر الإنترنت & 9 \\
\hline,+1 & $v \cdot, q$ & $\wedge, \wedge$ & $\wedge$ & 17,0 & 10 & $V \varepsilon, V$ & $\checkmark \wedge$ & تحقيق التواصل السلكي وإللاسلكي & $\vee$ \\
\hline, .1 & $00, \varepsilon$ & . & - & 11 & 1. & $\wedge 9$ & $\wedge 1$ & 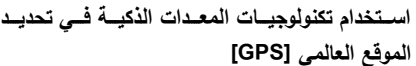 & $\wedge$ \\
\hline,+1 & $7 \wedge, 1$ & $\mathrm{v}, \mathrm{v}$ & 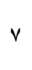 & $1 \wedge, V$ & iv & Vr, & $7 V$ & 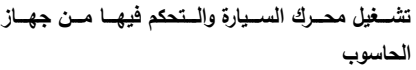 & 9 \\
\hline,+1 & or, r & $\cdot$ & - & $|r|$, & 11 & $\wedge 9,9$ & $\Lambda$. & لكبار السند في أجهزة الاستشعار في مراقبة الحالة الصحية & 1. \\
\hline, .1 & $r \leq, r$ & 0,7 & 10 & iv, 0 & 17 & V 7,9 & $\mathrm{v}$. & الارجة الكلية & \\
\hline
\end{tabular}

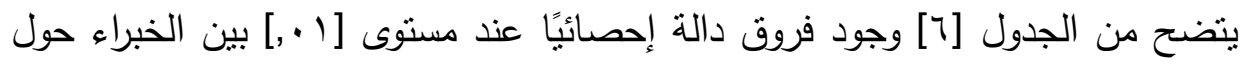
إسهامات بعض مجالات الاقتصاد الرقمي [إنترنت الأثثياء] في رقمنة التعليم الفني، لصالح الطلاب الذين قالوا [نعم].

(Atzori et al., 2010; وتأتي نتائج الدراسة الحالية متفقة مع نتائج دراسات

Mattern \& Floerkemeier, 2010; ITU, 2012; Porter \& Heppelmenn, 2014; Fleisch et al., 2014; Vermesan et al.,2014; الأثياء عبارة عن شبكة من الأثياء المادية التي ترتبط رقميا بالاستشعار Sense، والمراقبة الترات monitor والرؤية ومشاركة المعلومات وتيسير التخطيط، والتحكم، والتتسيق بين عمليات التوريد، ويتم

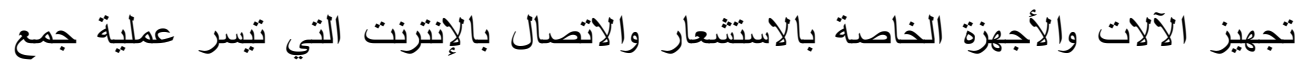
البيانات وتخزين هذه البيانات في الخدمات السحابية، حيث يمكن للقائمين على أمر التعليم الفني استخدام هذه البيانات في عمليات صنع القرارات، ويمكن لمعلم التعليم الفني الحصول

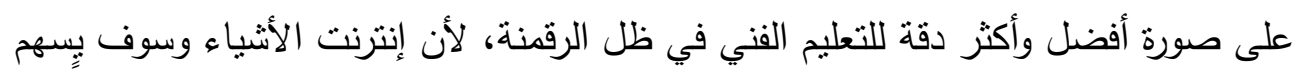

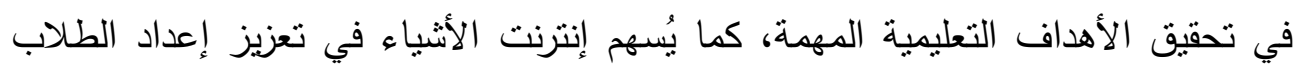

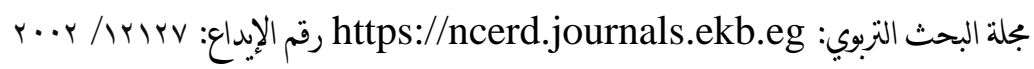

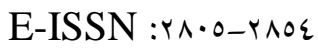

ISSN: $\cdot \wedge \Lambda \mu-I T \Lambda V$ 
للحياة العملية، وسلامة البيئة التعليمية، والمساهمة في تدعيم وتعزيز عمليات التعليم الذاتي للطلاب، وتدعيم فكرة التعلم النشط، وتحسين الاستخدام الفعال للموارد التعليمية، وتزويد

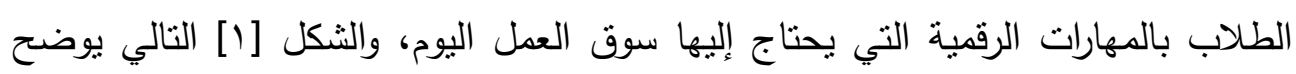
أبرز النتائج التي نم التوصل إليها في هذا الفرض:

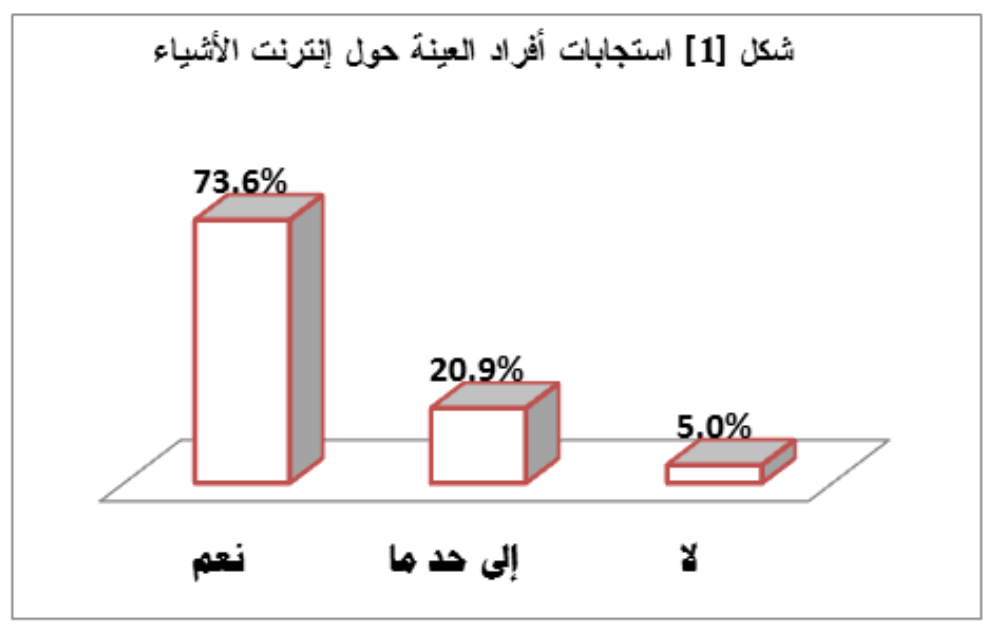

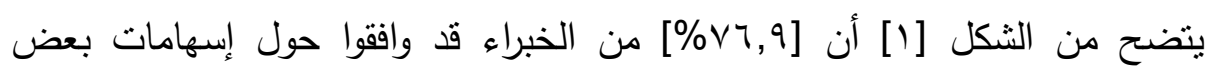

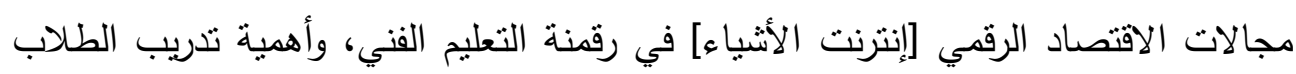
في التعليم الفني على كيفية استخدام إنترنت الأشياء. التحقق من صحة الفرض الثاني:

ينص الفرض الثاني على: "وجود فروق دالة إحصائيًا عند مستوى [1.,] في متوسطات استجابات الخبراء حول إسهامات بعض مجالات الاقتصاد الرقمي [تكنولوجيا الطائرة بدون طيار ] في رقمنة التعليم الفني"، وللتحقق من صحة الفرض تم استخدام [كاّب] لتعرف الفروق بين استجابات الخبراء حول إسهامات بعض مجالات الاقتصاد الرقمي [تكنولوجيا الطائرة بدون طيار ] في رقمنة التعليم الفني والموضحة بالجدول [V] التالي:

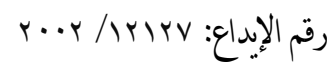

E-ISSN : $\ \wedge \cdot 0-Y \wedge 0 \varepsilon$ https://ncerd.journals.ekb.eg بجلة البحث التربوي: ISSN: $\cdot \wedge \Lambda \mu-17 \Lambda V$ 
إسهامات بصض بجالات الاقتصاد الرقمي في رقمنة التعليم الفني من وجهة نظر الخبراء

\section{جدول [V]}

التكرارات والنسب المئوية وقيمة [كاب] والدلالة في استجابات الخبراء حول إسهامات بعض مجالات الاقتصاد الرقمي [تكنولوجيا الطائرة بدون طيار] في رقمنة التعليم القني

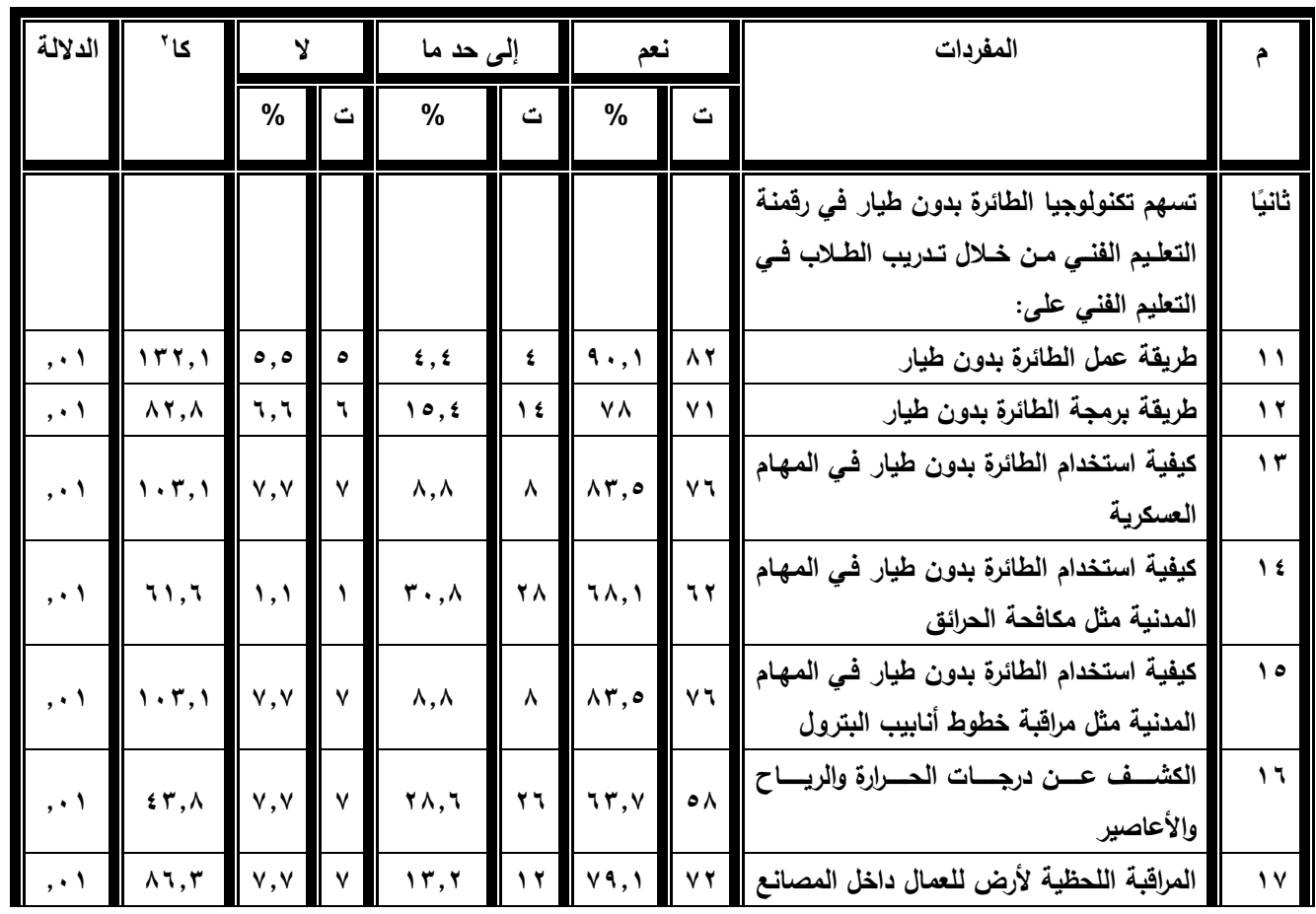

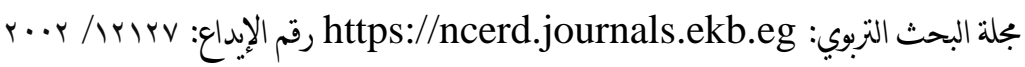

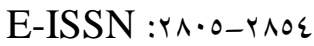

ISSN: $\cdot \wedge \Lambda \mu-I T \Lambda V$ 


\begin{tabular}{|c|c|c|c|c|c|c|c|c|c|}
\hline الدلالة & Sil & $y$ & & م حد ما & & عم & & المفردات & 5 \\
\hline,.+1 & 90,7 & $\varepsilon, \varepsilon$ & $\varepsilon$ & $1 \leq, r$ & ז & $\wedge,, r$ & $V \leqslant$ & الانقاذ البحري المعلومــات اللازمــة للقيـام بعمليـات & 11 \\
\hline,.+1 & $r_{0, \Lambda}$ & $\% 4$ & 7 & $\% 10, r$ & $1 \varepsilon$ & $\% \vee \wedge$ & vi & الارجة الكلية & \\
\hline
\end{tabular}

يتضح من الجدول [V] وجود فروق دالة إحصائيًا عند مستوى [ (, ب] بين الخبراء حول إسهامات بعض مجالات الاقتصاد الرقمي [تكنولوجيا الطائرة بدون طيار] في رقمنة التعليم الفني، لصالح الطلاب الذين قالوا [نعم]. وتأتي نتائج الدراسة الحالية متفقة مع نتائج دراسات (Alexandre Suzanne) Gibt ,2013; Preble ,2015; Birtchnell \& Gibson ,2015; Jordan ,2015; Stijn Poslema ,2015; Cruz Silva, 2016; Petrinjak, 2016; Mishra \& Koehler ,2016; Carnahan, 2016; Strimel, Barlholomew \& Kim, 2017; حg,\& Cheng ,2019; على تكنولوجيا الطائرات بدون طيار بيسر عمليات تعلم الطلاب ويزيد من انخراطهم ودافعية في التعلم، حيث بدأت هذه المشروعات في الثمانينات واستمرت حتى الآن وقد نم

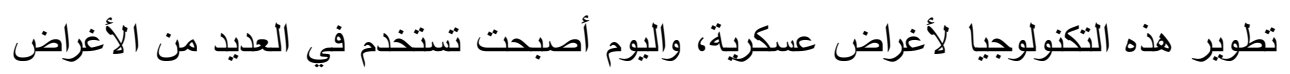
المدنية، وأصبح الابتكار في تكنولوجيا الطائرات بدون طيار بسير بوتيرة متسارعة، والطائرة بدون طيار هي عبارة طائرة بدون وجود طاقم وتعرف باسم المركبات الجوية غير المأهولة unmanned unscrewed aerial vehicles aircraft systems، هي بمثابة روبوت طائر يمكن التحكم فيه عن بعد أو الطيران بضرورة مستقلة من خلال خطط الطيران التي يتم التحكم فيها بواسطة البرامج في أنظمنها المدمجة، والتي تعمل جنبًا إلى جنب مع أجهزة الاستشعار الموجودة على مثن الطائرة

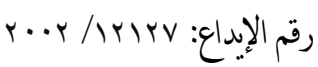

E-ISSN : $\curlyvee \wedge \cdot 0-\curlyvee \wedge \circ \varepsilon$ https://ncerd.journals.ekb.eg بلة البحث التربوي:

ISSN: $\cdot \wedge \wedge \mu-I T \wedge V$ 
إسهامات بعض بجالات الاقتصاد الرقي في رقمنة التعليم الفني من وجهة تظر الخبراء

ونظام تحديد المواقع العالمي GPS، كما يتم التحكم في الطائرة بدون طيار من خلال

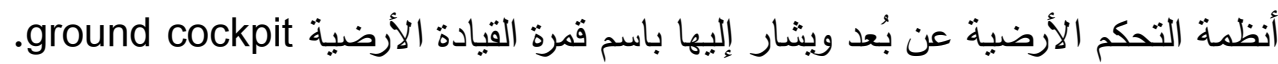

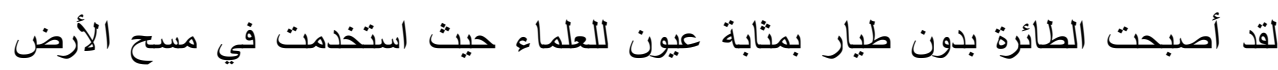

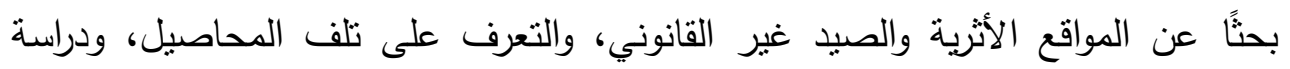

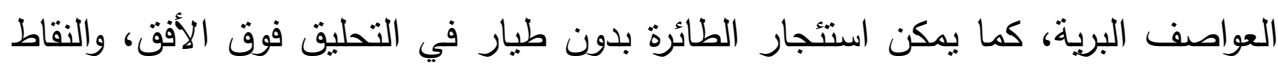

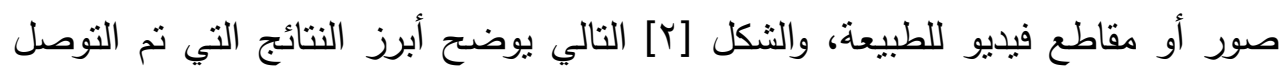

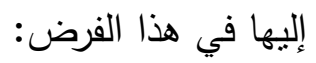

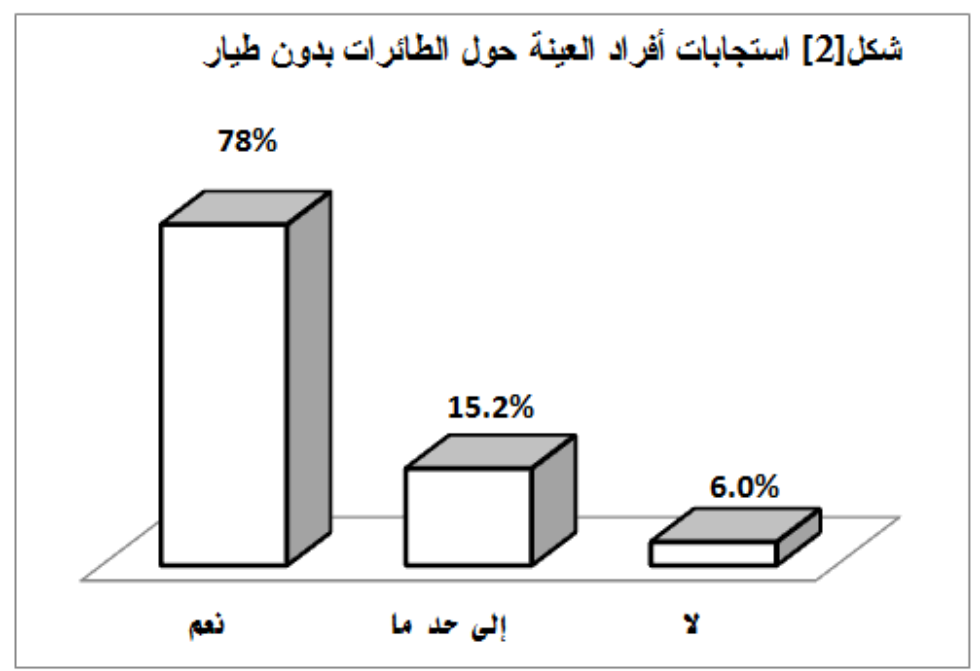

يتضح من الثنكل [r] أن [\% [\% من الخبراء قد وافقوا حول إسهامات بعض مجالات

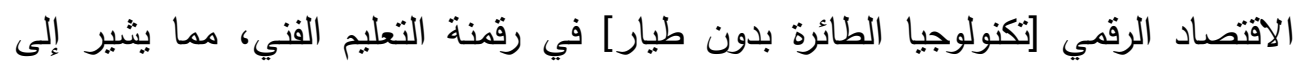

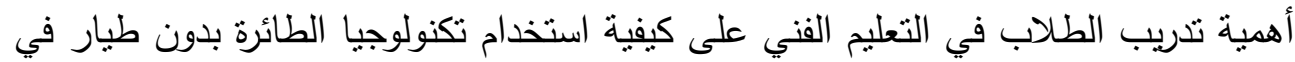

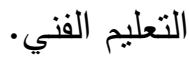

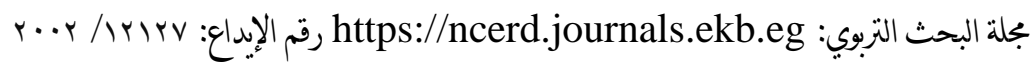

E-ISSN :YN・O-YNO\&

ISSN: $\cdot \wedge \Lambda T^{\prime}-17 \Lambda V$ 


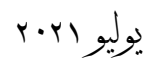

ينص الفرض الثالث على: "وجود فروق دالة إحصائيًا عند مستوى [1 .،] في متوسطات استجابات الخبراء حول إسهامات بعض مجالات الاقتصاد الرقمي [التسويق الرقمي] في

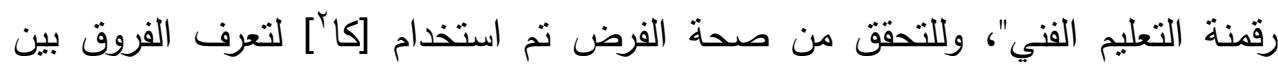
استجابات الخبراء حول إسهامات بعض مجالات الاقتصاد الرقمي [التسويق الرقمي] في رقمنة التعليم الفني والموضحة بالجدول التالي:

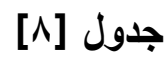

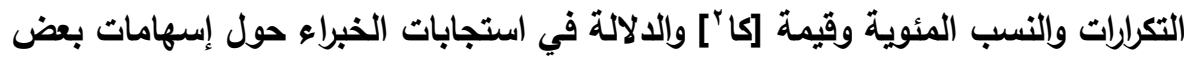

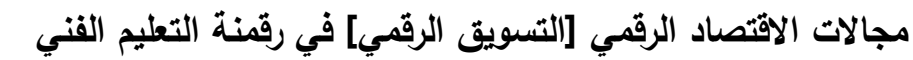

\begin{tabular}{|c|c|c|c|c|c|c|c|c|c|}
\hline \multirow[t]{2}{*}{ الدلالة } & \multirow[t]{2}{*}{ كا' } & \multicolumn{2}{|c|}{ ل } & \multicolumn{2}{|c|}{ إلى حد ما } & \multicolumn{2}{|c|}{ نعم } & \multirow[t]{2}{*}{ المفردات } & \multirow[t]{2}{*}{ p } \\
\hline & & $\%$ & $ت$ & $\%$ & ت & $\%$ & ت & & \\
\hline & & & & & & & & الفُسهم التسوق الرقمي في رقمنة التعليم & ثُالثًا \\
\hline, .1 & 07,9 & 7,7 & 7 & $r \leqslant, r$ & $r Y$ & $79, r$ & r & غـرس مهـارات التسـويق الرقمسي في & 19 \\
\hline, .1 & $\wedge \neg$, & $\wedge, \wedge$ & $\Lambda$ & $|r|$, & 11 & $\vee \vee, 1$ & Vr & 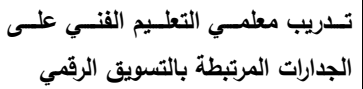 & $r$. \\
\hline, .1 & $\wedge r, \Lambda$ & 7,7 & 7 & $1 \mathrm{~T}, \varepsilon$ & $1 \varepsilon$ & $\vee \wedge$ & VI & 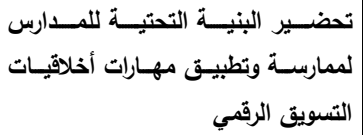 & rI \\
\hline,$\cdot 1$ & $r Y, r$ & 11 & 1. & $r \wedge, 0$ & ro & 0,0 & $\leqslant 7$ & تـــــيب الإدارة المدرسـية علـى آليـات & $r r$ \\
\hline, .1 & $\Lambda \cdot, \nearrow$ & $\varepsilon, \varepsilon$ & $\varepsilon$ & $1 \wedge, V$ & IV & $\vee \vee, q$ & V. & تعـــف الطــلاب أساســيات التســـيق & r \\
\hline, .1 & $\vee 7,1$ & $r, r$ & $r$ & $r r, l$ & YI & $V \varepsilon, V$ & 71 & تصميم المواقع الإكترونية العوامـل المهـــة فـي & $r \varepsilon$ \\
\hline
\end{tabular}

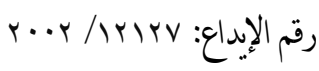

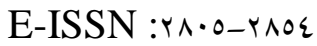

https://ncerd.journals.ekb.eg بكلة البحث التربوي:

ISSN: $\cdot \wedge \wedge \mu-I T \wedge V$ 
إسهامات بعض بجالات الاقتصاد الرقي في رقمنة التعليم الفني من وجهة تظر الخبراء

\begin{tabular}{|c|c|c|c|c|c|c|c|c|c|}
\hline \multirow[t]{2}{*}{ الدلالة } & \multirow[t]{2}{*}{ كا' } & \multicolumn{2}{|c|}{$\gamma$} & \multicolumn{2}{|c|}{ إلى حد ما } & \multicolumn{2}{|c|}{ نعم } & \multirow[t]{2}{*}{ المفردات } & \multirow[t]{2}{*}{ م } \\
\hline & & $\%$ & ت & $\%$ & ت & $\%$ & ت & & \\
\hline,+1 & $\wedge \varepsilon, Y$ & $\varepsilon, \varepsilon$ & $\varepsilon$ & 18,7 & 17 & $\vee \wedge$ & VI & تعــرف الطــلاب لمجــالات التســـويق & ro \\
\hline,+1 & $99, r$ & $\varepsilon, \varepsilon$ & $\varepsilon$ & 18,7 & 17 & $\vee \wedge$ & VI & تعرف الطلاب كيفية استخدام التقتيات & YY \\
\hline, .1 & $r q, q$ & $\% \bullet, 0$ & 0 & $\% r \cdot, q$ & 19 & $\% \vee r, ч$ & $7 V$ & الدرجة الكلية & \\
\hline
\end{tabular}

يتضح من الجدول [^] وجود فروق دالة إحصائيًا عند مستوى [1 •,] بين الخبراء حول إسهامات بعض مجالات الاقتصاد الرقمي [التسويق الرقمي] في رقمنة التعليم الفني، لصالح الطلاب الذين قالوا [نعم]. وتأتي نتائج الدراسة الحالية متفقة مع نتائج دراسات منل: : Noel,2009; WOODCO, 2013;Stoke, 2013; Dhote, Jog, Gavade\& Shrivastava ,2015; Pride\& Ferrel, 2016; Pineiro-Otero \& Martinez-Rolan, 2016; (Khausik ,2017; Get craft, 2017; Kusumawati, 2019) التسويق الرقمي يُعد من الأمور بالغة الأهمية اليوم لضمان نجاح الأعمال ويقوم على التواصل مع الجمهور في المكان المناسب الوقت المناسب باستخدام شبكة الإنترنت، ويشمل لإنه

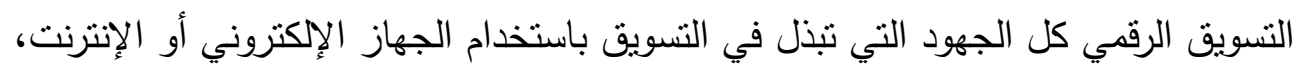
حيث تستفيد الثركات من القنوات الرقمية منل: محركات البحث Search engines، والوسائط الاجتماعية social media، والبريد الإكتروني، ومواقع الويب الأخرى للتواصل لتوفيه

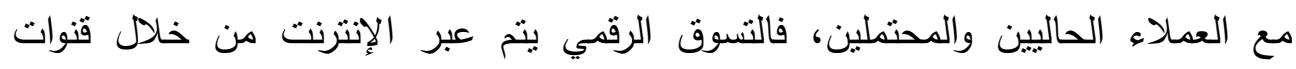
ومنصات وأساليب مختلفة سواء عبر موقع الويب الخاصة بالثركة أو عبر البريد الإلكتروني

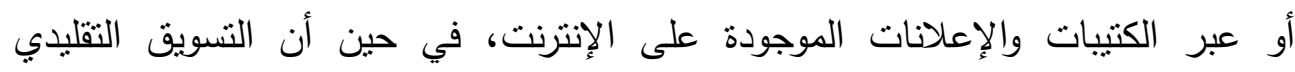

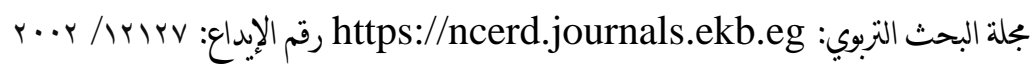

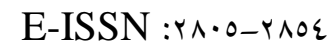

ISSN: $\cdot \wedge \Lambda \mu-I T \Lambda V$ 
traditional marketing التسويق المادي، ومن ثم فإن تدريب المعلمين والطلاب على بعض مجالات الاقتصاد الإعلاد

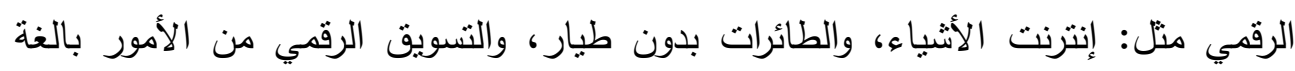

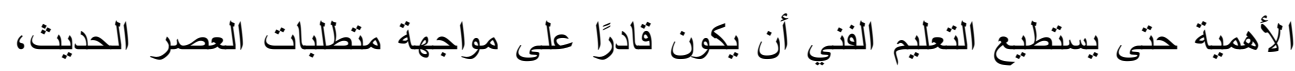

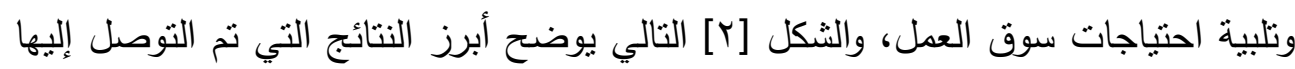
في هذا الفرض:

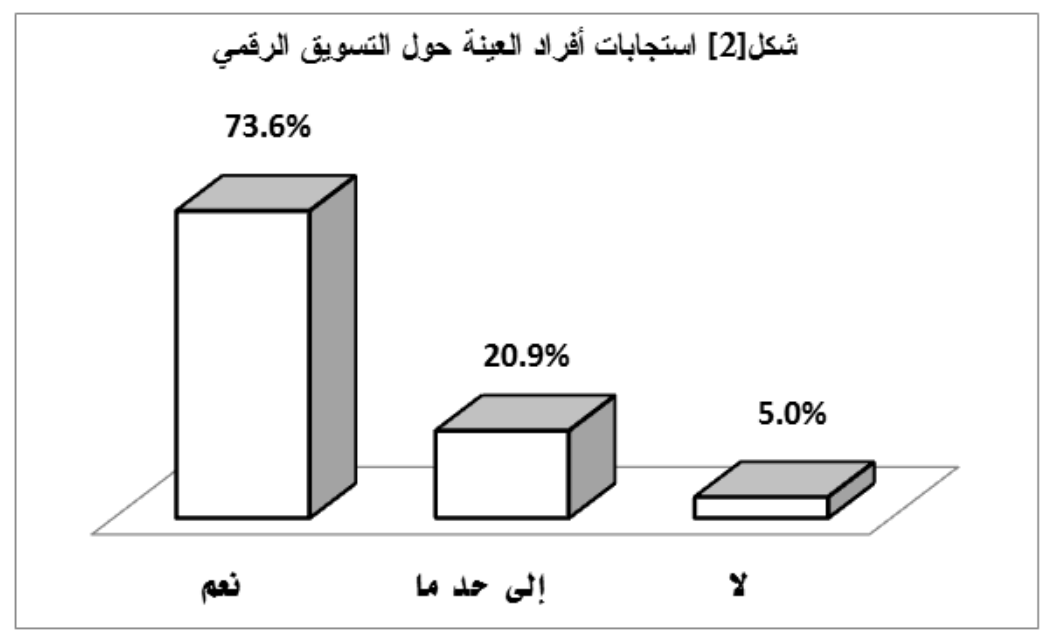

يتضح من الثكل [r] أن [T,\% مجالات الاقتصاد الرقمي [التسويق الرقمي] في رقمنة التعليم الفني، مما يشير إلى أهمية تدريب الطلاب في التعليم الفني على كيفية القيام بعمليات التسويق الرقمي عبر الإنترنت.

التوصيات:

ا. التحديث الاستباقي للمناهج الدراسية في التعليم الفني لدمج مجالات الاقتصاد الرقمي

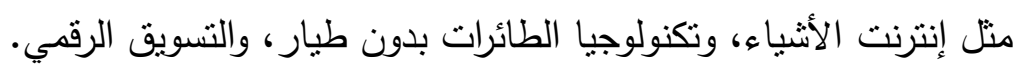


إسهامات بعض بجالات الاقتصاد الرقي في رقمنة التعلم الفني من وجهة ظظر الخبراء

r. تحديث اللوائح والقوانين التعليمية المتعلقة بالتدريب على التكنولوجيات الحديثة بهدف مواكبة السرعة في تطورات الرقمنة الجديدة.

r. إقامة تعاون وثيق بين الثركات والمدارس من أجل معالجة اتجاهات الرقمنة بصورة الركأ أفضل، وضمان تطوير المهارات الرقمية للطلاب ذات الصلة.

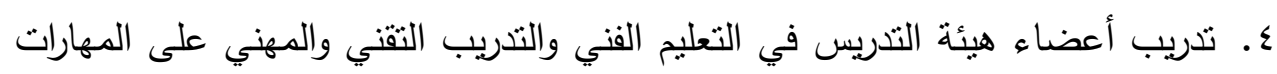
الرقمية وتزويدهم بالأدوات والمواد التعليمية المنطورة. ه. إعداد الطلاب لاستخدام التقنيات المتقدمة لجعل النعليم الفني جذابًا وملائمًا لاحتياجات سوق العمل.

4. تجهيز البنية التكنولوجية في المدارس الثانوية الفنية حتى تتمكن من تطبيق نظام

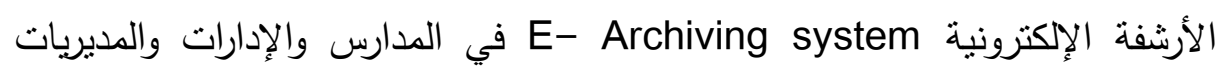
لتيسير الحصول على البيانات.

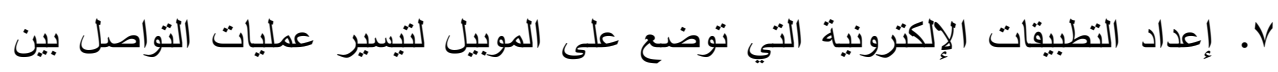
جميع العاملين داخل المدارس أو الإدارات أو المديريات أو بين المدارس لإسبر والإدارات والمديريات.

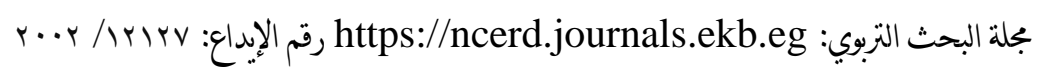

E-ISSN :Y^・0-Y^O\&

ISSN: $\cdot \wedge \Lambda \mu-17 \wedge \vee$ 


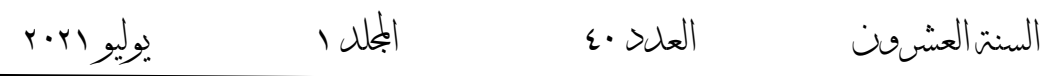

\section{المراجع}

أولاً: المراجع العربية:

بن نومي سليمة \& حياهم سعاد، بونار صفية (7 ( ب). الاستخدامات المدنية للطائرات بدون طيار ، رسالة ماجستير، قسم علوم الإعلام والاتصال والمكتبات، كلية العلوم

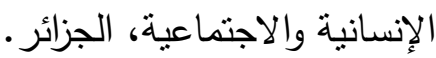

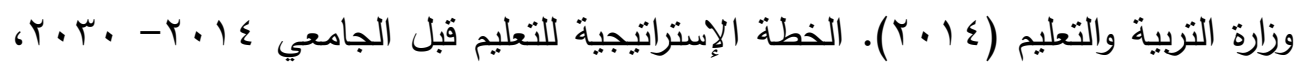
القاهرة.

Adelakun, O. A., Oviawe, J. I., \& Barfa, G. I. (2015). Strategies for enhancing female participation in Technical, Vocational Education and Training (TVET) in Nigeria. Advances in Social Sciences Research Journal, 2(4),110-120.

Atzori L, Iera A, Morabito G (2010) The internet of things: a survey. Comput Netw 54:2787-2805

Bakeeva, L., Pastukhova, E., \& Romanova, Y. (2019, September). Education in the digital economy: students' view. In International Conference on Digital Technologies in Logistics and Infrastructure (ICDTLI 2019) (pp. 257-261). Atlantis Press.

Becker, G.S., Murphy, K. M., \& Tamura, R. (1994). Human capital, fertility, and economic growth. In G.S. Becker (Ed), Human capital: A theoretical and empirical analysis with special reference to education (pp. 323-350). Chicago: The University of Chicago Press.

Bejinaru, R. (2017). Knowledge strategies aiming to improve the intellectual capital of universities. Management \& Marketing. Challenges for the Knowledge Society, 12(3), 500-523.

Bitkom Research; Central Association of German Crafts (2017). Digitalization of the craft. Presentation material: Rohleder, B. \& Schulte K. Berlin. Retrieved March 2, 2017, from https://www.zdh.de/

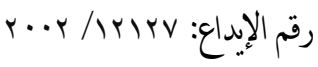

E-ISSN :YN・O-YNO\&
بلة البحث الزبوي: https://ncerd.journals.ekb.eg

ISSN: $\cdot \wedge \wedge r-17 \wedge v$ 
إسهامات بعض بجالات الاقصاد الرقمي في رقمنة التعليم الفني من وجهة نظر الخبراء

fileadmin / user upload / Bitkom-ZDH-Charts-zur-Digitisierung-desHandwerks-02-03-2017-final.pdf

British Computer Society, (2014). The Digital Economy, British Computer

Society, London. https://policy.bcs.org/sites/policy.bcs.org/files/digital $\% 20$ economy \%20 Final\%20version_0.pdf.

Brolpito, A. (2018). Digital Skills and Competence, and Digital and Online Learning. Turin: European Training Foundation. Retrieved January 1, 2020, from https://- www.etf.europa.eu/sites/default/files/201810/DSC\%20and \%20DOL_0.pdf

Bukht, R., \& Heeks, R. (2017). Defining, conceptualising, and measuring the digital economy. Development Informatics working paper, (68).

Busse, J., Lange, A., \& Schumann, M. (2019). Effects of digitalization on vocational education and training: First results of a qualitative study. DELFI 2019.

Carnahan, C., Zieger, L., \& Crowley, K. (2016). Drones in education: Let your students' imagination soar. Arlington, Virginia: International Society for Technology in Education.

Carretero, S., Vuorikari, R., \& Punie, Y. (2017). DigComp 2.1: The Digital Competence Framework for Citizens. With Eight Proficiency Levels and Examples of Use. Luxembourg: Publications Office of the European Union

Chaffey, D., \& Ellis-Chadwick, F. (2019). Digital marketing. Pearson UK.

Cruz Silva, J. A. (2016). Is Ecuador prepared to deploy drone journalism?

Dahlman, C., Mealy, S. \& Wermelinger, M., (2016). Harnessing the Digital

Economy for Developing Countries, OECD, Paris. http://www.oecdilibrary. org/docserver /download/4adffb24-en.pdf

Dhote, T., Jog, Y., Gavade, N., \& Shrivastava, G. (2015). Effectiveness of digital marketing in education: An insight into consumer perceptions. Indian Journal of Science and Technology, 8(S4), 200205.

Dougherty, m. Shaun (2016). Career and technical education in high school: does it improve student outcomes? The Thomas B. Fordham Institute.

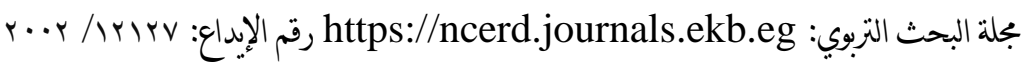

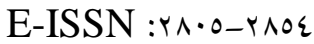

ISSN: $\cdot \wedge \Lambda \mu-I T \Lambda V$ 
Douse M., Uys P. (2019) TVET Teaching in the Time of Digitisation. In:

McGrath S., Mulder M., Papier J., Suart R. (eds) Handbook of Vocational Education and Training. Springer, Cham.

Dronepedia. (2017). Types of drones. Retrieved November 29, 2018, from

Dronepedia: https://dronepedia.xyz/5-different-types-of-drones.

European Commission (2017). Final Communication From The Commission

To The European Parliament And The Council A Fair And Efficient

Tax System In The European Union For The Digital Single Market.

https://ec.europa.eu/taxation_customs/sites/taxation/files/communicatio

n_taxation_digital_single_market_en.pdf

European Commission (2019). A European approach to Artificial intelligence. https://digital-strategy.ec.europa.eu/en/policies/europeanapproach-artificial-intelligence.

Fleisch E, Weinberger M, Wortmann F (2014) Business models for the internet of things. Bosch lab white paper. http://www.iot-lab. ch/wpcontent/uploads/2014/09/EN_Bosch-Lab-White-PaperGM-im-IOT1_1.pdf

GetCraft.com. (2017). 'White Paper Final: Indonesia's Digital and Content Marketing Reports in 2017,' GetCraft.com. Retrieved from https://www. slideshare. net/digitalinasia /indonesia-digital.

Goddard, K., Roudsari, A., \& Wyatt, J. C. (2012). Automation Bias: A Systematic Review of Frequency, Effect Mediators, and Mitigators. Journal of the American Medical Informatics Association JAMIA, 19(1), 121-127.

Goldberg, D., Corcoran, M., \& Picard, R. G. (2013). Remotely piloted aircraft systems and journalism: Opportunities and challenges of drones in news gathering.

House of Commons, (2016). The Digital Economy, House of Commons Business, Innovation and Skills Committee, London. https://www.publications. parliament.uk/pa/cm201617/cmselect/cmbis/87/87.pdf

ITU (2012) New ITU standards define the internet of things and provide the blueprints for its development. http://www.itu.int/ ITU-

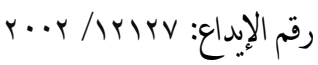

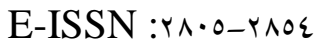

https://ncerd.journals.ekb.eg بكلة البحث التربوي:

ISSN: $\cdot \wedge \Lambda \mu-17 \Lambda V$ 
إسهامات بعض بجالات الاقصاد الرقي في رقمنة التعليم الفني من وجهة ظر الخبراء

T/newslog/New? ITU? Standards? Define? The? Internet? Of? Things? And? Provide? The? Blueprints? For? Its? Develo pment.aspx.

Jordan, B. R. (2015). A bird's-eye view of geology: The use of micro drones/UAVs in geologic fieldwork and education. GSA Today, 25(7), 42-43.

Kaushik, S. (2017). 'Current Digital Marketing Stats and Trends in Education Industry," accessed on January 28th 2018 from https:// arm world wide.com/currentdigital-marketing-stats-and-trends-ineducationindustry/.

Kusumawati, A. (2019). Impact of digital marketing on student decisionmaking process of higher education institution: A case of Indonesia. Journal of e-Learning and Higher Education.

Laanpere, M. (2019). Recommendations on Assessment Tools for Monitoring Digital Literacy within UNESCO's Digital Literacy Global Framework. Information Paper No. 56. Montreal, Canada

Lee, D. (2018). China's bungled drone display breaks world record. Retrieved November 29, 2018, from BBC News: https://www.bbc.com/news/technology-43982522.

Machekhina, O.N. (2017). Digitalization of education as a trend of its modernization and reforming. Revista Espacios, 38(40), 26.

Martin, C. M. (2015). 'Social Media Engagement and Collegiate Recruitment: An Examination of the Use of Social Networks in the College Recruitment and Student Choice Processes', Dissertations. Paper 93.

Mattern F, Floerk emeier C (2010) From the internet of computers to the internet of things. Informatik-Spektrum 33(2):107-121.

Mertens, P. \& Wiener, M. (2018). Riding the Digitalization Wave: Toward a Sustainable Nomenclature in Wirtschaftsinformatik - A Comment on Riedl et al. (2017). Business \& Information Systems Engineering, 60(4), 367-372.

Mgabhi, G., \& Mohammed, M. (2018). Economic benefits of technical vocational education and training in the Kingdom of Eswatini: A case

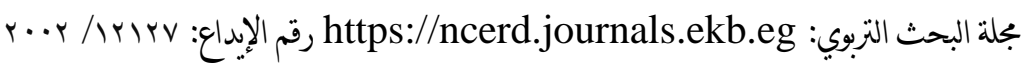

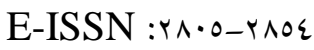

ISSN: $\cdot \wedge \Lambda \mu-I T \Lambda V$ 
of the national handicraft training centre. African Review of Economics and Finance, 10(2), 169-192.

Natalya, M., Alexey, K., \& Alexander, L. (2018, December). Analysis of Elearning in Digital Economy. In 4th International Conference on Economics, Management, Law and Education (EMLE 2018) (pp. 866870). Atlantis Press.

Ng, W. S., \& Cheng, G. (2019). Integrating Drone Technology in Stem Education: A Case Study to Assess Teachers' readiness And Training Needs. Issues in Informing Science \& Information Technology, (16).

Noel, H. (2009). Basic marketing 01: Consumer Behavior. Switzerland: AVA Publishing SA. Retrieved from https://eshraghtranslators.com/educatio n/storage/book/uqQ7IpTPfpmulRotD4ui cRv7FajN7uaI1Bbq1UXO.pdf

Pearcy, M. (2015). "They're always over us" - Teaching about drones. The Social Studies, 106(3), 126-137.

Petrinjak, L. (2016). Using drones to enhance STEM learning. NSTA Reports, 27(8), 8-9.

Piñeiro-Otero, T., \& Martínez-Rolán, X. (2016). Understanding digital marketing - basics and actions. In MBA (pp. 37-74). Springer, Cham.

Porter ME, Heppelmann JE (2014) How smart, connected products are transforming competition. Harv Bus Rev 92:11-64

Preble, B. C. (2015). A case for drones. Technology and Engineering Teacher, 74(7), 24-29.

Romano, M. (2014). Drones as lifesavers. The Science Teacher, 81(3), 14.

Schmidt, M., Makhkamova, A., Spilski, J., Berg, M., Pietschmann, M., Exner, J. P., \& Lachmann, T. (2020). 3 Competence Development with Digital Learning Stations in VET in the Crafts Sector. Research in Vocational Education edited by Eveline Wuttke• Jürgen Seifried Volume 4, 39.

Stone, M., \& Woodcock, N. (2013). Social intelligence in customer engagement. Journal of Strategic Marketing, 21(5), 394-401.

Strimel, G. J., Bartholomew, S. R., \& Kim, E. (2017). Engaging children in engineering design through the world of quadcopters. Children's Technology and Engineering, 7-11.

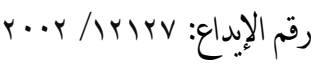

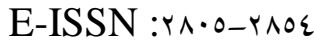

https://ncerd.journals.ekb.eg بحلة البحث التربوي:

ISSN: $\cdot \wedge \Lambda \mu-17 \Lambda \vee$ 
إسهامات بصض بجالات الاقصاد الرقمي في رقمنة التعليم الفني من وجهة نظر الخبراء

Stuart, K. (2014). What every parent needs to know about video games: a crash course. Retrieved on May 6, 2020, from https://www.theguardian. com/technology/ 2014/jun/02/parents-guidevideogames-playstationxbox-wii-apps-children.

Vermesan O, Friess P, Guillemin P, Sundmaeker H, Eisenhauer M, Moessner K, Arndt M, Spirito M, Medagliani P, Giaffreda R, Gusmeroli S, Ladid L, Serrano M, Hauswirth M, Baldini G (2014) Internet of things strategic research and innovation agenda. In: Vermesan $\mathrm{O}$, Friess $\mathrm{P}$ (eds) Internet of things - from research and innovation to market deployment. River Publishers, Aalborg, pp 7-142.

Wapmuk, L. S. (2011). Technical, vocational education and training for sustainable development of 137 ctober. A keynote address presented at the $24^{\text {th }}$ annual national conference of October 137 association of teachers of technology (NATT) at the federal college of education (technical), umunze, $17^{\text {th }}-21^{\text {st }} 137$ ctober.

Wolf, T. \& Strohschen, J.H. (2018). Digitization: definition and maturity. Computer Science Spectrum, 41 (1), 56-64.

Wortmann, F., \& Flüchter, K. (2015). Internet of things. Business \& Information Systems Engineering, 57(3), 221-224.

Young, Toby (2018). Technically Gifted: How Selection Can Save Technical and Vocational Education Centre for Policy Studies. Cps.org.uk.

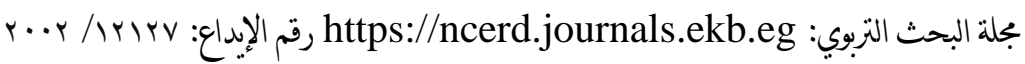

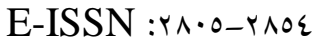

ISSN: $\cdot \wedge \Lambda \mu-I T \Lambda V$ 